\title{
1991 Yearly Calibration of
} Pacific Northwest Laboratory's Gross Gamma-Ray Borehole Geophysical Logging System

\author{
R. J. Arthur
}

August 1991

Prepared for

the U.S. Department of Energy

under Contract DE-AC06-76RLO 1830

Pacific Northwest Laboratory

Operated for the U.S. Department of Energy

by Battelle Memorial Institute

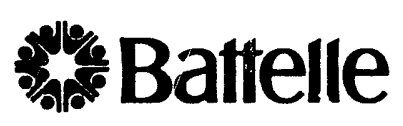




\title{
DISCLAIMER
}

This report was prepared as an account of work sponsored by an agency of the United States Government. Neither the United States Government nor any agency thereof, nor Battelle Memorial Institute, nor any of their employees, makes any warranty, expressed or implied, or assumes any legal liability or responsibility for the accuracy, completeness, or usefulness of any information, apparatus, product, or process disclosed, or represents that its use would not infringe privately owned rights. Reference herein to any specific commercial product, process, or service by trade name, trademark, manufacturer, or otherwise does not necessarily constitute or imply its endorsement, recommendation, or favoring by the United States Government or any agency thereof, or Battelle Memorial Institute. The views and opinions of authors expressed hercin do not necessarily state or reflect those of the United States Government or any agency thereof.

\author{
PACIFIC NORTHWEST LABORATORY \\ operated by \\ BATTELLE MEMORIAL INSTITUTE \\ for the \\ UNITED STATES DEPARTMENT OF ENERGY \\ under Contract DE-ACO6-76RLO 1830
}

\author{
Printed in the Urified States of America
}

Available to DOE and DOE contractors from the

Office of Scientific and Technical Information, P.O. Box 62, Oak Ridge, IN 37831; prices available from (615) 576-8401. FTS 626-8401.

Available to the public from the National Technical Information Service, U.S. Department of Commerce, 5285 Port Royal Rd., Springfield, VA 22161. 
PNL- -7785

DE92 000391

A Research Report for

Westinghouse Hanford Company

1991 YEARLY CALIBRATION OF PACIFIC

NORTHWEST LABORATORY'S GROSS GAMMA-RAY

BOREHOLE GEOPHYSICAL LOGGING SYSTEM

R. J. Arthur

August 1991

Prepared for

the U.S. Department of Energy

under Contract DE-AC06-76RLO 1830

Pacific Northwest Laboratory

Richland, Washington 99352

\section{MASTER}

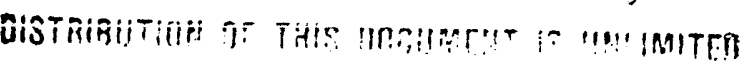




\section{SUMMARY}

This report describes the 1991 yearly calibration of a gross gamma-ray geophysical pulse logging system owned by the U.S. Department of Energy (DOE) and operated by the Pacific Northwest Laboratory. The calibration was conducted to permit the continued use of this system for geologic and hydrologic studies associated with remedial investigations at the Hanford Site.

Primary calibrations to equivalent uranium units were conducted in DOE borehole model standards that reside on the Hanford Site. The calibrations were performed in borehole models SBL/SBH and SBA/SBB, which contain lowequivalent uranium concentrations .

Correlations were established based on two similar approaches for relating observed count rate in before- and after-logging field calibrations to equivalent uranium concentrations.

A new field source (Ra-20S-82) was fabricated to replace the old source (Ra-20S-204), whose activity led to variable fitld calibration results previously caused by a nonfixed geometry. A cross-calibration study was performed to compare the operation of the new source relative to the old source.

A digitally based collection/recording system was recently acquired, so that many of the procedures were performed with the old analog system and the new digital systeni to compare the performance of the digital system. 


\section{CONTENTS}

SUMMARY . . . . . . . . . . . . . . . . . . . . . . i i . . . .

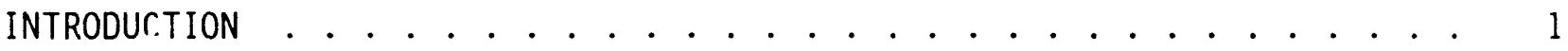

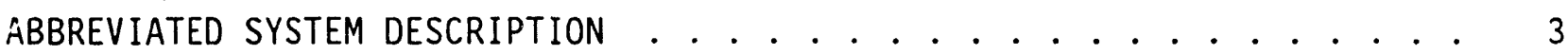

INSTRUMENTATION CALIBRATION . . . . . . . . . . . . . . . 5

PULSE GENERATOR . . . . . . . . . . . . . . . . . . 5

RATE METERS ........................ . . . 5

CHART RECORDER . . . . . . . . . . . . . . . . . . . 7

DEPTH-INDICATING EQUIPMENT . . . . . . . . . . . . . . . . 8

DEAD-TIME DETERMINATION . . . . . . . . . . . . . . . . . 11

CURRENT MEASURED VALUE ........................ 11

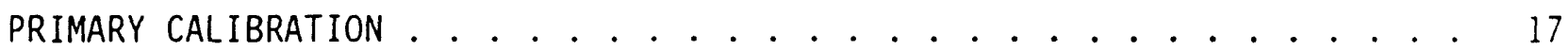

SBL/SBH AND SBA/SBB BOREHOLE MODEL CALIBRATIONS . . . . . . . . . . 17

LINEARITY DETERMINATION . . . . . . . . . . . . . . . 18

FIELD SOURCE CORRELATION ....................... 19

CONCLUSIONS . . . . . . . . . . . . . . . . . . . . . . . . 21

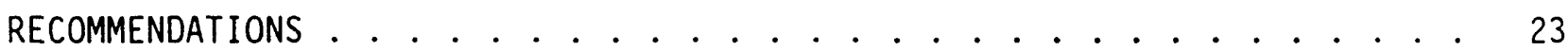

REFERENCES ........................... . . 25

APPENDIX A - DATA FROM INSTRUMENT CALIBRATION MEASUREMENTS . . . . . . . A.l

APPENDIX B - DATA FROM DEAD-TIME DETERMINATION MEASUREMENTS . . . . . . B.l

APPENDIX C - DATA FROM PRIMARY CALIBRATION MEASUREMENTS . . . . . . . . C. C

APPENDIX D - DATA FROM FIELD SOURCE CROSS-CALIBRATION MEASUREMENTS . . . D.1 


\section{FIGURES}

1 Deviation of Observed Chart Recorder Reading from Expected Reading .. . . . . . . . . . . . . . . . . . . 9

2 Multiplicative Factor Required to Convert Observed Chart Recorder Reading to Actual Reading................. . 10

\section{TABLES}

1 Recorder Output Voltage from Rate Meter RMM208 Serial No. 185. . . . 6

2 Recorder Output Voltage from Rate Meter RMM208 Serial No. 182. . . 6

3 Results from Calibration of Chart Recorder Against a known Input Voltage ....................... . 8

4 Data Used for Recalibration of Dead-Time Correction Values. . . . . 12

5 Summary of Measured Dead-Time Correction Vaiues. . . . . . . . . . 13

6 Data Used from Previous Recalibration of Dead-Time Correction Values . . . . . . . . . . . . . . . . 15

7 Radioelement Assay Data for SBL and SBA Zones in the SBL/SBH and SBA/SBB Standard Borehole Models. . . . . . . . . . . . . 17

8 Probe Constant of Proportionality for SBL and SBA Zones . . . . . 18

9 Data Used to Cross-Correlate 01d Field Source with New Field Source... . . . . . . . . . . . . . . . 20 


\section{INTRODUCTION}

This report presents the yearly calibration of a gross gamma-ray geophysical pulse logging system owned by the U.S. Department of Energy (DOE) and operated by Pacific Northwest Laboratory (PNL). (a) The initial base calibration of the system is described in a previous report (Brodeur and Koizumi 1989), from which one can obtain a more thorough understanding of the basic function of the system.

The purpose of the yearly base calibration is to verify the quality of data obtained in the field. The system calibration involved in this report includes: 1) a check of basic instrumentation calibration (i.e., rate meters, strip chart recorder, signal generator, and depth-indicating equipment); 2) a check of the system dead time; 3) two primary calibrations using both the $\mathrm{SBL} / \mathrm{SBH}$ and the SBA/SBB borehole models; 4) the use of a portable field source correlated to the primary standards to establish a unit of measure; and 5) a series of cross-calibration measurements to establish the behavior of a new field source (Ra-20S-82), whose radioactivity is in a geometry known to be fixed, relative to the old field source (Ra-20S-204), whose geometry was discovered to be variable (Arthur 1990).

(a) Pacific Northwest Laboratory is operated by Battelle Memorial Institute for the U.S. Department of Energy under Contract DE-AC06-76RLO 1830. 


\section{ABBREVIATED SYSTEM DESCRIPTION}

The PNL gross gamma-ray logging system consists of a thallium-doped sodium iodide [NaI(TI)] detector encased within a ruggedized probe, a winchand-cable system for probe placement and high-voltage/signal transmission, a pulse rate meter, and a chart recorder. Ancillary equipment located within the mobile laboratory mounted on a vehicle includes a pulse generator, a highvoltage power supply, and diagnostic instrumentation. A more detailed description of the logging system can be found in the Gearhart-Owen Industries instruction manual for pulse logging systems (Gearhart-Owen, Not Dated).

The signals sent from the detector probe provide no information concerning the energy of detected gamma rays. A nuvistor located within the probe serves as a discriminator to set the energy cutoff value for signal generation. A univibrator located within the gamma-ray probe generates a constant voltage pulse that is sent along the $5000-\mathrm{ft}-1$ ong cable. A $2-V$ triangular pulse with a full-width at half maximum of approximately $14 \mu \mathrm{s}$ arrives at the input of the rate meter. The rate meter employs a userselected time constant to average statistical fluctuations of the incoming count rate. An analog voltage is generated for the chart recorder and is proportional to the input count rate. The chart recorder generates a hardcopy record of the data for subsequent analysis.

A digitally based system was recently acquired from Colog Inc., Golden, Colorado, and installed by a field representative. The digital system is connected to a personal computer-compatible card located within the 8-bit slot of a COMPAQ SLT 386/S20. The digital system currently serves as a backup recording device similar to the analog chart recorder. 


\section{INSTRUMENTATION CALIBRATION}

The critical instrumentation for the gross gamma-ray probe geophysical pulse logging system includes: 1) a pulse generator for establishing scale integrity; 2) a rate meter to collect signals coming uphole, to average statistical fluctuations, and to create an analog voltage output; 3 ) a chart recorder or equivalent output medium to provide a hard-copy record of detected probe activity; and 4 ) depth-indicating equipment.

\section{PULSE GENERATOR}

The calibration of the pulse generator was performed by checking the output over several ranges against a calibrated frequency counter. The resulting data are provided in Appendix $A$. The data indicate excellent accuracy and precision in operation at all settings. The maximum observed deviation was $0.006 \%$, which exceeds any realistic requirements for current well-1ogging activities.

\section{RATE METERS}

The rate meters were calibrated by disconnecting both the chart recorder and the digital recorder system. The rate meter time constant was set at $1 \mathrm{~s}$, and the attenuation and output potentiometers were locked at the standard operating value of 10 . Pulses from the pulse generator were fed into the cable to the line input of the rate meters (so that the cable/rate meter system was being calibrated) and the rate meter direct current output was measured with a calibrated voltmeter.

The base calibration report (Brodeur and Koizumi 1989) and the subsequent yearly calibration report (Arthur 1990) verified that both rate meters have a linear response. The data for similar measurements are contained in Appen$\operatorname{dix} A$ and a summary of the results are in Tables 1 and 2 . The results verify that the stability and the linear response of both rate meters have not changed during the past year [i.e., voltage measurements on rate meter RMM208 Serial No. 185 indicated a maximum variability in the output voltage of $0.22 \%$ full-scale counts/s and a measured linearity of $0.0017894 \pm 0.21 \%$, compared to $0.001788 \pm 0.05 \%$ (see Arthur 1990); voltage measurements on rate meter RMM208 
IABLE 1. Recorder Output Voltage from Rate Meter RMM208 Serial No. 185

\begin{tabular}{|c|c|c|c|c|c|c|c|}
\hline \multirow{2}{*}{$\begin{array}{l}\text { Time } \\
\text { Const. } \\
(s) \\
\end{array}$} & \multirow{2}{*}{$\begin{array}{c}\text { Full-Scale } \\
\text { Input } \\
(\mathrm{Hz}) \\
\end{array}$} & \multicolumn{4}{|c|}{$\begin{array}{l}\text { Voltage Output as } \\
\% \text { of Full-Scale Input }\end{array}$} & \multirow{2}{*}{$\begin{array}{l}\text { Linearity } \\
\text { Constant } \\
\left(\times 10^{2}\right) \\
\end{array}$} & \multirow{2}{*}{$\begin{array}{l}\text { Zerg } \\
\left(\times 10^{2}\right) \\
\end{array}$} \\
\hline & & $10 \%$ & $20 \%$ & $50 \%$ & $100 \%$ & & \\
\hline $\begin{array}{l}1 \\
1 \\
1 \\
1 \\
1 \\
1\end{array}$ & $\begin{array}{r}100 \\
500 \\
1000 \\
5000 \\
10000 \\
50000\end{array}$ & $\begin{array}{l}0.0176 \\
0.0178 \\
0.0178 \\
0.0179 \\
0.0178\end{array}$ & $\begin{array}{l}0.0357 \\
0.0357\end{array}$ & $\begin{array}{l}0.0891 \\
0.0893 \\
0.0894\end{array}$ & $\begin{array}{l}0.1786 \\
0.1786 \\
0.1789 \\
0.1789 \\
0.1789 \\
0.1790\end{array}$ & $\begin{array}{l}0.17889 \\
0.17875 \\
0.17901 \\
0.17900 \\
0.17889 \\
0.17912\end{array}$ & $\begin{array}{l}-0.00031 \\
-0.00015 \\
-0.00014 \\
-0.00010 \\
-0.00001 \\
-0.00012\end{array}$ \\
\hline Average & & 0.01778 & 0.0357 & 0.08927 & 0.1788 & 0.178944 & -0.000137 \\
\hline Maximum & deviation & 0.0003 & 0.0001 & 0.0003 & 0.0004 & 0.00037 & 0.00030 \\
\hline Maximum & deviation (\%) & 1.7 & 0.28 & 0.33 & 0.22 & 0.21 & $>100$ \\
\hline Maximum & observed vol & ge outpl & devi & $\begin{aligned} \text { on } & =0 \\
& =0\end{aligned}$ & $04 / 0$ & cale co & \\
\hline Maximum & observed 1 in & arity d & ation & $\begin{array}{l}=0 \\
=0\end{array}$ & $03,0$. & $\begin{array}{l}34 \\
\text { counts/s }\end{array}$ & \\
\hline
\end{tabular}

TABLE 2. Recorder Output Voltage from Rate Meter RMM208 Serial No. 182

\begin{tabular}{|c|c|c|c|c|c|c|c|}
\hline \multirow{2}{*}{$\begin{array}{l}\text { Time } \\
\text { Const. } \\
(\mathrm{s}) \\
\end{array}$} & \multirow{2}{*}{$\begin{array}{l}\text { Full-Scale } \\
\text { Input } \\
\text { (Hz) } \\
\end{array}$} & \multicolumn{4}{|c|}{$\begin{array}{l}\text { Voltage Output as } \\
\% \text { of Full-Scale Input }\end{array}$} & \multirow{2}{*}{$\begin{array}{r}\text { Linearity } \\
\text { Constant } \\
\left(\times 10^{2}\right) \\
\end{array}$} & \multirow{2}{*}{$\begin{array}{l}\text { Zerg } \\
\left(\times 10^{2}\right)\end{array}$} \\
\hline & & $10 \%$ & $20 \%$ & $50 \%$ & $100 \%$ & & \\
\hline $\begin{array}{l}1 \\
1 \\
1 \\
1 \\
1 \\
1\end{array}$ & $\begin{array}{r}100 \\
500 \\
1000 \\
5000 \\
10000 \\
50000\end{array}$ & $\begin{array}{l}0.0182 \\
0.0183 \\
0.0182 \\
0.0183 \\
0.0183\end{array}$ & $\begin{array}{l}0.0362 \\
0.0362\end{array}$ & $\begin{array}{l}0.0900 \\
0.0900\end{array}$ & $\begin{array}{l}0.1794 \\
0.1796 \\
0.1799 \\
0.1799 \\
0.1799 \\
0.1799\end{array}$ & $\begin{array}{l}0.17911 \\
0.17925 \\
0.17957 \\
0.17965 \\
0.17957 \\
0.17958\end{array}$ & $\begin{array}{l}0.00027 \\
0.00035 \\
0.00030 \\
0.00025 \\
0.00030 \\
0.00031\end{array}$ \\
\hline Average & & 0.01826 & 0.0362 & 0.08993 & 0.17977 & 0.179455 & 0.000297 \\
\hline Maximum & deviation & 0.0001 & 0.0 & 0.0002 & 0.0005 & 0.00054 & 0.00010 \\
\hline Maximum & deviation (\%) & 0.55 & 0.0 & C.22 & 0.28 & 0.30 & 34 \\
\hline Maximum & observed volt & age outpu & t devia & $\begin{aligned} \text { ion } & =0 . \\
& =0 .\end{aligned}$ & $05 / 0.17$ & $\begin{array}{l}77 \\
\text { cale cou }\end{array}$ & \\
\hline Maximum & observed line & arity de & ation & $\begin{array}{l}=0 \\
=0\end{array}$ & $54 / 0$ & $\begin{array}{l}9455 \\
\text { counts/s }\end{array}$ & \\
\hline
\end{tabular}


Serial No. 182 indicated a maximum variability in the output voltage of $0.28 \%$ full-scale counts/s and a measured linearity of $0.0017945 \pm 0.30 \%$, compared to $0.001788 \pm 0.05 \%$ (see Arthur 1990)]. Measured 1 inearity refers to a leastsquares fit of output voltage versus percentage of full-scale input.

The error in both rate meters is insignificant for any logging measurements to be made with this system.

\section{CHART RECORDER}

The chart recorder consistently reads zero on the strip chart for no input and full scale for full input. However, the recorder reads approximately $51 \%$ for input, which is half of full scale. Because of the strict 1 inearity for the rate meters, as indicated in Tables 1 and 2, it was previously concluded (Arthur 1990) that the chart recorder had a nonlinear response in the middle region.

A more thorough chart recorder calibration was performed using a calibrated voltage standard. The actual test data are contained in Appendix A.

The nonlinear behavior of the chart recorder is evident in the data presented in Table 3. A graph showing the percent deviation of the observed reading relative to the expected reading is illustrated in Figure 1 . A maximum error of $1.4 \%$ is found in the $30 \%-40 \%$ of full-scale region. Figure 2 is a graph based on the data in Table 3 of the multiplicative factor needed to convert a count rate observed on the chart recorder to true count rate. Such a conversion is generally only required on measurements that are very sensitive to count rate fluctuations, such as dead-time measurements. The calibration was performed in one direction only, starting with zero input voltage and progressing to full-scale input voltage $(0.17980 \mathrm{~V})$, so that none of the chart recorder hysteresis noted previously (Arthur 1990) could be quantitated. 
TABLE 3. Results from Calibration of Chart Recorder Against a Known Input Voltage

\begin{tabular}{lcc}
$\begin{array}{c}\text { Input } \\
\text { Voltage } \\
(V)\end{array}$ & $\begin{array}{c}\text { Observed Chart } \\
\text { Recorder Reading } \\
\text { (in.) }\end{array}$ & $\begin{array}{c}\text { Deviation from } \\
\text { Expected Reading } \\
(\%)\end{array}$ \\
\cline { 2 - 3 } 0.0 & 0.0 & 0.0 \\
0.01798 & 1.002 & 0.2 \\
0.03596 & 2.020 & 1.0 \\
0.05394 & 3.043 & 1.43 \\
0.07192 & 4.057 & 1.42 \\
0.08990 & 5.063 & 1.27 \\
0.10788 & 6.072 & 1.19 \\
0.12586 & 7.073 & 1.05 \\
0.14384 & 8.053 & 0.67 \\
0.16182 & 9.037 & 0.41 \\
0.17980 & 10.017 & 0.20
\end{tabular}

\section{DEPTH-INDICATING EQUIPMENT}

The depth-indicating and chart recorder control equipment were checked against depth, as measured with a calibrated steel tape. Data collected during the measurement are contained in Appendix $A$.

At a depth of $400.0 \mathrm{ft}$, as indicated by the chart recorder, the mechanical depth indicator showed $400.0 \mathrm{ft}$ and the steel tape showed $399.85 \mathrm{ft}$. The maximum absolute deviation of the tape depth from the indicated depth was between 300 and $350 \mathrm{ft}$, amounting to $0.22 \mathrm{ft}$ in $300 \mathrm{ft}$ or $0.07 \%$ of the indicated depth. Such a deviation is similar to the error reported in the base calibration report (Brodeur and Koizumi 1989). 


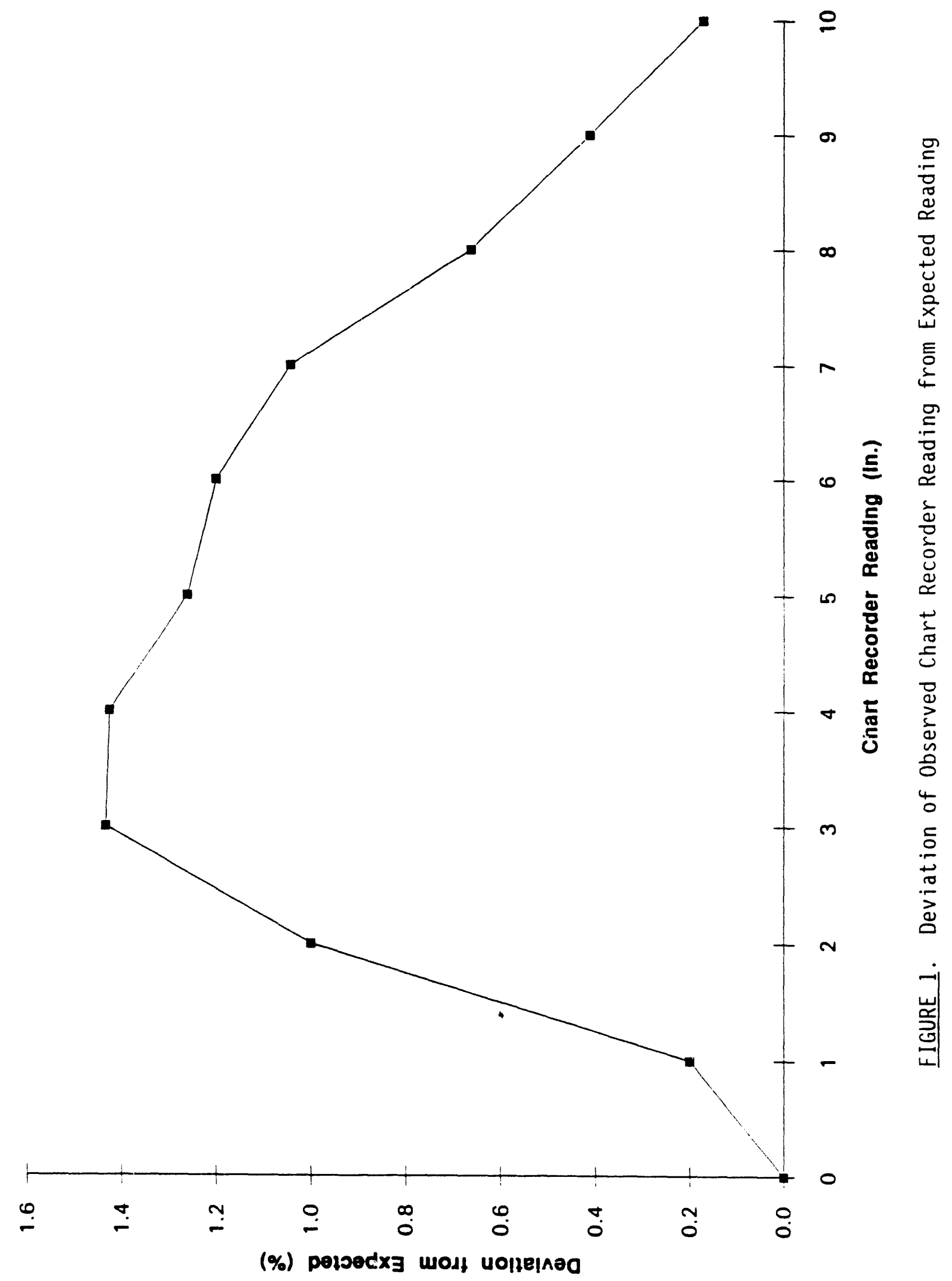




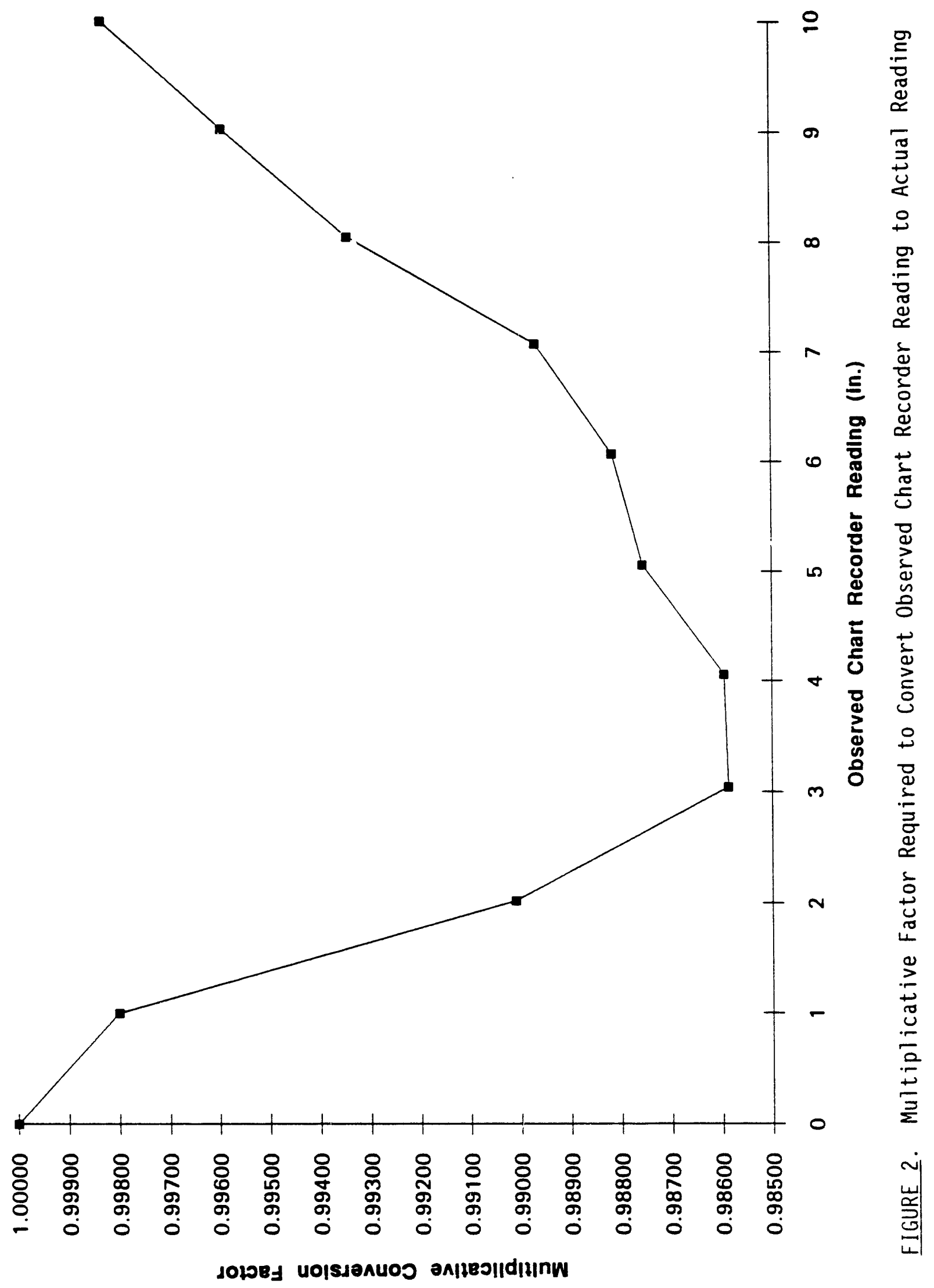




\section{DEAD-TIME DETERMINATION}

\section{CURRENT MEASUIKED VALUE}

With the results of the chart recorder calibration in mind, data were collected to compute a more rigorous value for the dead-time correction. A summary of the observed data are presented in Table 4, and the resulting deadtime correction values are given in Table 5 . Uncertainties associated with the dead-time correction values are caused by count rate uncertainties only and are computed by summing the uncertainties in quadrature (Bevington 1969). The two-source method described in the base calibration document (Brodeur and Koizumi 1989; Scott 1980) was used for the experiment. The scale was not changed during the course of any one run for the series of measurements (source 1 only, both sources, source 2 only, and background).

The technique employed in the current measurements used two radium secondary field calibration sources placed at equal distances, such that each $0.020-\mathrm{mC} i$ source gave an equivalent reading on the chart recorder when counted individually, which met the one simplifying assumption used in the two-source method described by Scott (1980).

The experimental procedure used is staightforward. First, the two sources were placed adjacent to each other. Then, source 2 was removed to a significant distance and a 1.5- to 2.0-min count rate was recorded. Then, source 2 was placed at the corresponding measured distance on the opposite side and another 2 -min count of the combined rates was recorded. Next, source 1 was removed and the count rate was recorded with only source 2 in place. Finally, source 2 was removed and a background count rate was recorded on the same scale. The approximate dead-time correction for the system was calculated as follows:

$$
t_{\text {approx. }}=\frac{2\left(N_{1}+N_{2}-N_{12}\right)}{\left(N_{1}+N_{2}\right) \cdot N_{12}}
$$

where $N_{1}=$ background-corrected count rate with only source 1

$\mathrm{N}_{2}$ = background-corrected count rate with on? y source 2 $\mathrm{N}_{12}$ = background-corrected count rate with both sources. 
TABLE 4. Data Used for Recalibration of Dead-Time Correction Values Chart Recorder Chart Recorder

Value Type - Rate (observed) Rate (corrected)

Scale $=10 \mathrm{~K}$ counts $/ \mathrm{s}$ Background (B)

$$
\begin{aligned}
& \mathrm{N}_{1}+\mathrm{B} \\
& \mathrm{N}_{2}+\mathrm{B} \\
& \mathrm{N}_{12}+\mathrm{B}
\end{aligned}
$$

55

5435

5410

10075

Scale $=50 \mathrm{~K}$ counts $/ \mathrm{s}$ Background

$\mathrm{N}_{1}+\mathrm{B} 53$

$\mathrm{N}_{2}^{1}+\mathrm{B} 54$

$\mathrm{N}_{12}^{2}+\mathrm{B} 102$

Scale $=10 \mathrm{~K}$ counts $/ \mathrm{s}$ Background

$$
\begin{aligned}
& \mathrm{N}_{1}+\mathrm{B} \\
& \mathrm{N}_{2}+\mathrm{B} \\
& \mathrm{N}_{12}+\mathrm{B}
\end{aligned}
$$

Scale $=5 \mathrm{~K}$ count $: \mathrm{s}$

Background

$$
\begin{aligned}
& N_{1}+B \\
& N_{2}+B \\
& N_{12}+B
\end{aligned}
$$

Scale $=5 K$ counts $/ \mathrm{s}$

Background

$N_{1}+B$
$N_{2}+B$
$N_{12}^{2}+B$

Scale $=5 K$ counts $/ \mathrm{s}$

Background

$\mathrm{N}_{1}+\mathrm{B}$

$\mathrm{N}_{2}+\mathrm{B}$

$\mathrm{N}_{12}^{2}+\mathrm{B}$
50

2795

2830

5480

70

2845

2765

$>5150$

50

1430

1345

2775

50

2425

2275

4555
55.

5369 .

5344 .

10060 .

50.

5159.

5251 .

10042.

50.

2756 .

2791 .

5413.

70.

2824.

2746 .

$\mathrm{N} / \mathrm{A}$

50.

1397.

1312 .

2731 .

50.

2394.

2245.

4470 . 
TABLE 5. Summary of Measured Dead-Time Correction Values

$\begin{array}{ccc}\text { Scale Used } & \begin{array}{c}t_{\text {approx }}(\mu \mathrm{S}) \\$\cline { 2 - 2 } $10 \mathrm{~K}\end{array} & \frac{t_{\text {exact }}}{(\mu \mathrm{S})} \\ 50 \mathrm{~K} & 11.27 \pm 2.73 & 11.99 \pm 3.10^{(\mathrm{a})} \\ 10 \mathrm{~K} & 6.17 \pm 2.79 & 6.38 \pm 2.98 \\ 5 \mathrm{~K} & 5.82 \pm 7.22 & 5.91 \pm 7.45 \\ 5 \mathrm{~K} & \mathrm{~N} / \mathrm{A} & \mathrm{N} / \mathrm{A} \\ 5 \mathrm{~K} & -20.6 \pm 21.4 & -20.0 \pm 20.3 \\ & 11.86 \pm 9.59 & 12.19 \pm 10.10\end{array}$

(a) Recommended value $=12.0 \pm 3.1$.

The exact dead-time correction is then obtained using a second formula.

$$
t_{\text {exact }}=\frac{1-\left(1-2 \cdot N_{12} \cdot t_{\text {approx. }}\right)^{1 / 2}}{N_{12}}
$$

The chart recorder data from the dead-time measurements are contained in Appendix $B$, and the values and scale settings used to compute the dead-time correction are given in Table 4 . The observed rate from the chart recorder is contained in the first column of Table 4 . The second column of Table 4 contains the rate corrected for the chart recorder nonlinearity using multiplicative factors interpolated from the data shown in Figure 2.

To illustrate the need for correcting for chart recorder nonlinearity, consider the first set of measurements, where $N_{1}=5380, N_{2}=5355$, and $\mathrm{N}_{12}=10020$. These data yield $\mathrm{t}_{\text {approx. }}=13.29 \mu \mathrm{s}$ and $\mathrm{t}_{\text {exact }}=14.32 \mu \mathrm{s}$. When corrected for chart recorder nonlinearity, the value of $t_{\text {exact }}=11.97 \mu \mathrm{s}$ is obtained, which corresponds to a $20 \%$ error in the dead time resulting from only a $1.3 \%$ error in the chart recorder nonlinearity.

The dead-time correction value as reported in the base calibration report (Brodeur and Koizumi 1989) was not corrected for the chart recorder 
nonlinearities. Additionally, the scale was changed when recording the count rate for the combined sources, so that the high reading could not be read as accurately.

The dead-time value determined in the previous calibration report (Arthur 1990) used a less accurate correction for chart recorder nonlinearities, which were not reflected in the associated uncertainties.

The dead-time correction value of $12 . \mathrm{C}_{\mu} \mathrm{s}$ obtained from the first $10 \mathrm{~K}$ scale set of measurements (see Table 4 ) is probably the most representative value obtained in the past 3 years of measuremenis. Values computed by measurements on other scales and at different count rates suffer from either difficulty in precisely reading the count rate from the chart recorder output (at high count rates on high scales), sometimes coupied with the effects of hysteresis in the chart recorder, or insufficient statistics as a result of low count rates (low count rates on lower scales). Measurements taken on the lok scale without switching to other scales will probably always give the most accurate dead-time correction value. For example, using data from the previous report (Arthur 1990) on the 10K scale, one obtains a dead-time correction value of $12.2 \mu \mathrm{s}$ as shown by the data in Table 6.

A more stable and linsar recording device would aid in the accurate determination of the true system dead time. The newly acquired digital system is a likely candidate for such requirements but would need to be evaluated to verify linearity.

The experimentally determined dead time is consistent with the GearhartOwen Industries instruction manual (Gearhart-Owen, Not Dated), which states that "a 1500" length of cable permits gross counting rates of over 70,000 counts per second" [corresponding to a dead time of $14.3 \mu \mathrm{s}$ ]. A discrepancy does exist, however, in that the dead time alone does not explain the saturation of the system at the maximum count rate of 14500 counts/s originally observed in the course of the base calibration study (Brodeur and Koizumi 1989) when counting high gamma-ray fields. A maximum, well in excess of 70000 co:nts/s, is predicted when the dead time of $12 \mu \mathrm{s}$ is the sole source of the system saturation. 
TABLE 6. Data Used from Previous Recalibration of Dead-Time Correction Values

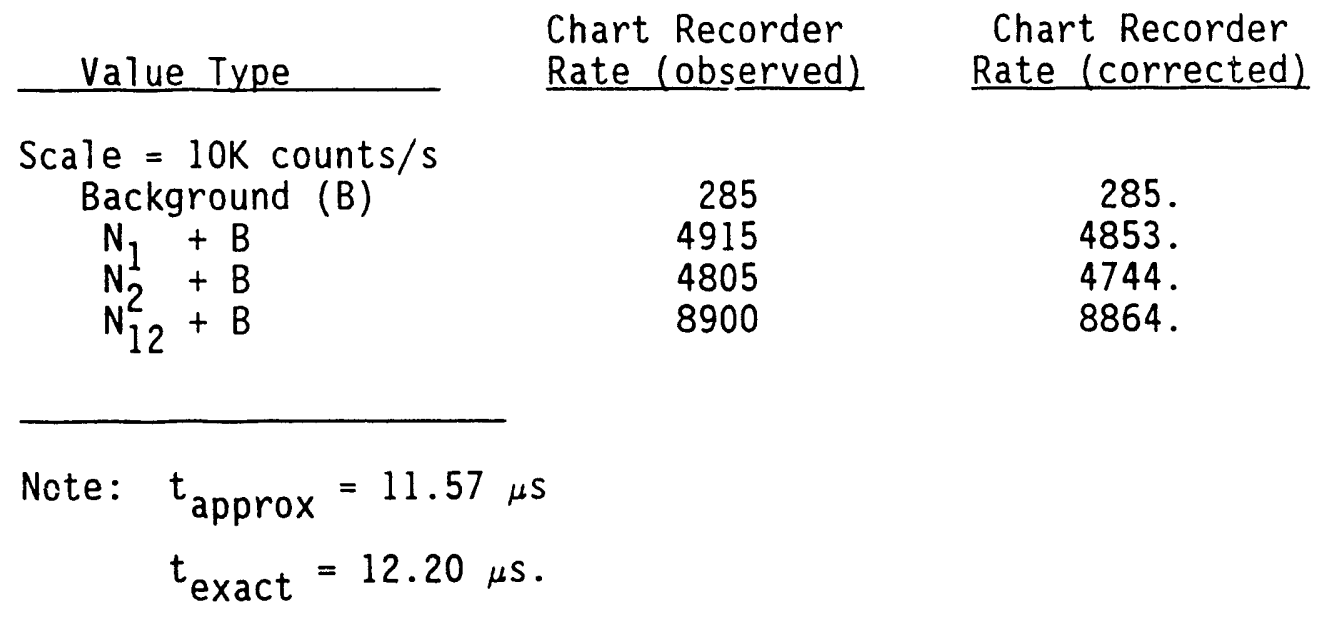




\section{PRIMARY CALIBRATION}

\section{SBL/SBH AND SBA/SBB BOREHOLE MODEL CALIBRATIONS}

The primary calibration was performed just outside the 200 West Area of the Hanford Site, where the borehole models had been moved from the DOE's Spokane field calibration facility. The calibration was performed using first the SBL/SBH and then the SBA/SBB standard borehole models. Complete descriptions of the models and the radioelement assays are provided in steele and George (1986). The pertinent equivalent concentrations of uranium with associated uncertainties are given in Table 7.

The calibrations were performed on March 21, 1991. Only the SBA and SBL zones gave useful recordings on both the $10 \mathrm{~K}$ and the 50K scales. The SBB and SBH zones saturated the logging system equipment at an apparent 15000 counts/s.

The field calibration source readings following the primary calibration runs revealed that the probe had an excess of counts, indicating some mild external contamination consistent with events during the 1990 primary calibrations (Arthur 1990). The source of the contamination was later shown to be radon adhering to the cool surface of the probe. It is suggested that the probe be encased in a polyethylene bag for future calibration runs.

TABLE 7. Radioelement Assay Data for SBL and SBA Zones in the SBL/SBH and SBA/SBB Standard Borehole Models

\begin{tabular}{|c|c|c|c|}
\hline Zone & ${ }^{226} \mathrm{Ra}(\mathrm{pCi} / \mathrm{g})$ & $\begin{array}{l}\text { Concentration } \\
\text { (equivalent uranium ppm) }\end{array}$ & Thickness (ft) \\
\hline BL & $324.0 \pm 9$ & $971.0 \pm 27$. & 4.00 \\
\hline & $61.2 \pm 1.7$ & $183.0 \pm 5$. & 4.01 \\
\hline
\end{tabular}




\section{LINEARITY DETERMINATION}

The appropriate method for determining the probe constant of proportionalicy uses measured equivalent uranium values from both models:

$P^{\prime}=$ (equivalent uranium in model $A$ - equivalent uranium in model $B$ ) $(R A-R B)$

where $P^{\prime}=$ probe constant of proportionality

$R A, R B=$ dead-time corrected count rate in models $A$ and $B$, respectively.

The value for the probe constant determined from using the two separate borehole models is presented in Table 8.

TABLE 8. Probe Constant of Proportionality for SBL and SBA Zones

$\begin{array}{lccc}\text { Zone } & \begin{array}{c}\text { Apparent } \\ \text { Count Rate } \\ \text { (counts/s) }\end{array} & \begin{array}{c}\text { Dead-Time Correction } \\ \text { Count Rate } \\ \text { (counts/s) }\end{array} & \\ \text { SBL } & 9945 \pm 100 & 11267 \pm 128 & \begin{array}{c}\text { Equivalent Uranium } \\ \text { Concentration (ppli) }\end{array} \\ \text { SBA } & 2286 \pm 46 & 2349 \pm 49 & 971 \pm 27\end{array}$

Note: Probe constant (equivalent uranium $\mathrm{ppm} /$ count $/ \mathrm{s}$ ) $=0.0884$

Linear intercept constant (equivalent uranium ppm) $=-24.6$ 


\section{FIELD SOURCE CORRELATION}

The method currently being used for field source calibration is described in Environmental Investigations Instruction 11.1, Appendix A, Rev. 1 (WHC 1991). The calibration procedure is to place the gamma-ray probe in a pipe clamp such that the probe is a minimum of $2 \mathrm{ft}$ away from any solid matter to minimize any excess count rate caused by variable amounts of backscatter.

The net apparent values (corrected ior background but uncorrected for dead time) used for Positions 1 and 2 control purposes on data collected after May 4, 1991, are 3466 and 608 counts/s, respectively.

Field calibration values obtained during the primary calibration are contained in Appendix $C$. The net apparent values for Positions 1 and 2 of 3553 and 617 counts/s agree, verifying a consistency of probe behavior.

A series of measurements was also performed on December 12, 1990, using the old ( $\mathrm{Ra}-20 \mathrm{~S}-204)$ and new (Ra-20S-82) radium field calibration sources to obtain a cross calibration of the two sources. Data from these crosscalibration measurements are contained in Appendix $D$ and are summarized in Table 9.

The recommended net apparent count rates for use of the new field source (Ra-20S-82) for Positions 1 and 2 are 3364 and 727 counts/s, respectively. The acceptable ranges to satisfy the $8 \% 1$ imit are $(3094$ - 3633) and (669 786) counts/s, respectively. 
IABLE 9. Data Used to Cross Correlate 01d Field Source with New Field Source 01d Source Ra-20S-204 New Source Ra-20S-82 Gross Count Rate (counts/s) Gross Count Rate (counts/s)

Identification Pos. 1 Pos. 2 Background Pos. 1 Pos. 2 Background

$\begin{array}{lllllll}\text { GA0 } & 3620 & 666 & 47.5 & 3160 & 780 & 47.5 \\ \text { GA1 } & 3620 & 665 & 46 & 3450 & 775 & 47 \\ \text { GA2 } & 3590 & 660 & 49 & 3375 & 770 & 46.5 \\ \text { GA3 } & 3545 & 659 & 46.5 & 3420 & 772 & 45 \\ \text { GA4 } & 3490 & 679 & 44 & 3395 & 775.5 & 47.5 \\ \text { GA5 } & 3500 & 666 & 45 & 3425 & 786 & 46.5 \\ \text { GA6 } & 3590 & 665 & 45.5 & 3400 & 765 & 45 \\ \text { GA7 } & 3580 & 658.5 & 45 & 3385 & 770 & 45 \\ \text { GA8 } & 3580 & 647 & 46.5 & 3405 & 774 & 45.5 \\ \text { GA9 } & 3550 & 653 & 46.5 & 3380 & 765.5 & 45\end{array}$

Net Count Rate (counts/s) Net Count Rate (counts/s)

\begin{tabular}{|c|c|c|c|c|}
\hline GAO & 3572.5 & 618.5 & 3412.5 & 732.5 \\
\hline GAl & 3574 & 619 & 3403 & 728 \\
\hline GA2 & 3541 & 611 & 3328.5 & 723.5 \\
\hline GA3 & 3498.5 & 612.5 & 3375 & 727 \\
\hline GA4 & 3446 & 635 & 3347.5 & 728 \\
\hline GA5 & 3455 & 621 & 3378.5 & 739.5 \\
\hline GA6 & 3544.5 & 619.5 & 3355 & 720 \\
\hline GA7 & 3535 & 613.5 & 3340 & 725 \\
\hline GA8 & 3533.5 & 600.5 & 3359.5 & 728.5 \\
\hline GA9 & 3503.5 & 606.5 & 3335 & 720.5 \\
\hline age $=$ & 3520.4 & 615.7 & 3363.5 & 727.3 \\
\hline ation & 44.2 & 9.3 & 28.4 & 5.8 \\
\hline & & $8 \%$ lower limit $=$ & 3094.4 & 669.1 \\
\hline & & $8 \%$ upper 1 imit $=$ & 3632.6 & 785.5 \\
\hline
\end{tabular}




\section{CONCLUSIONS}

The original dead-time correction was calculated as $7.4 \mu \mathrm{s}$ from data in which a change of scale was made and without any correction for chart recorder nonlinearity (Brodeur and Koizumi 1989). A new value was determined the next year as $17 \mu \mathrm{s}$, but with a fairly large uncertainty because of all approximate correction for the nonlinear response of the chart recorder readings. A current recommended value of $12.0 \mu \mathrm{s}$ is based on anaiog data that have been more accurately corrected for nonlinear response.

The raw primary calibration data have not significantly changed since they were determined and documented most recently (Arthur 1990): a gross count rate of 9945 colints/s, determined on the $10 \mathrm{~K}$ scale for the SBL/SBH borehole model, compared to 9980 counts/s last year. The calculated probe constant of 0.0884 equivalent uranium $\mathrm{ppm} /$ counts/s and the intercept of -24.6 equivalent uranium ppm reflect a more thorough calibration of the chart recorder.

A cross-calibration experiment between the old field source (Ra-20S-204) anc the new field source (Ra-20S-82) gave for the new source net apparent count rate values for Positions 1 and 2 of 3364 and 727 counts/s, respectively; the corresponding $8 \%$ ranges are $(3094$ - 3633) and (669 - 786) counts/s, respectively.

The potential for increased accuracy and ease of working with numbers generated using a digital system point to the need for evaluating the digital system as a replacement for the chart recorder as the recording medium. 


\section{RECOMMENDATIONS}

The following recommendations should be considered for implementation in 1991:

- calibrate an additional gamma-ray probe and/or system as a backup

- use the digital collection system as the primary data collection instrumentation, possibly with the chart recorder as a secondary (confirmation) or backup system

- perform an additional series of dead-time correction measurements using the digital recorder system if that system is linear

- ensheath the probe in polyethylene during calibration in the borehole models. 


\section{REFERENCES}

Arthur, R. J. 1990. 1990 Yearly Calibration of Pacific Northwest Laboratory's Gross-Gamma Borehole Geophysical Logging System. PNL-7460, Pacific Northwest Laboratory, Richland, Washington.

Bevington, P. R. 1969. Data Reduction and Error Analysis for the Physical Sciences. McGraw-Hill Book Co., New York, New York.

Brodeur, J. R., and C. J. Koizumi. 1989. Base Calibration of Pacific Northwest Laboratory's Gross Gamma Borehole Geophysical Logging System. WHC-EP-0246, Westinghouse Hanford Company, Richland, Washington.

Gearhart-Owen Industries, Inc. Not Dated. Instruction Manual: Pulse Logging Systems. Fort Worth, Texas.

Scott, J. H. 1980. "Pitfalls in Determining the Dead Time of Nuclear We11Logging Probes." Trans. Soc. Prof. Well Log. Ana7. (SPWLA), 21 st Annu. Logging Symp., pp. 1-11.

Steele, W. D., and D. C. George. 1986. Field Calibration Facilities for Environmental Measurements of Radium, Thorium, and Potassium, 2nd ed. GJ/TMC-01, Bendix Field Engineering Corporation, Grand Junction, Colorado.

WHC (Westinghouse Hanford Company). 1991. Environmental Investigations and Site Characterization Manual. WHC-CM-7-7, Revision \#35, Richland, Washington. 
APPENDIX A

DATA FROM INSTRUMENT CALIBRATION MEASUREMENTS 


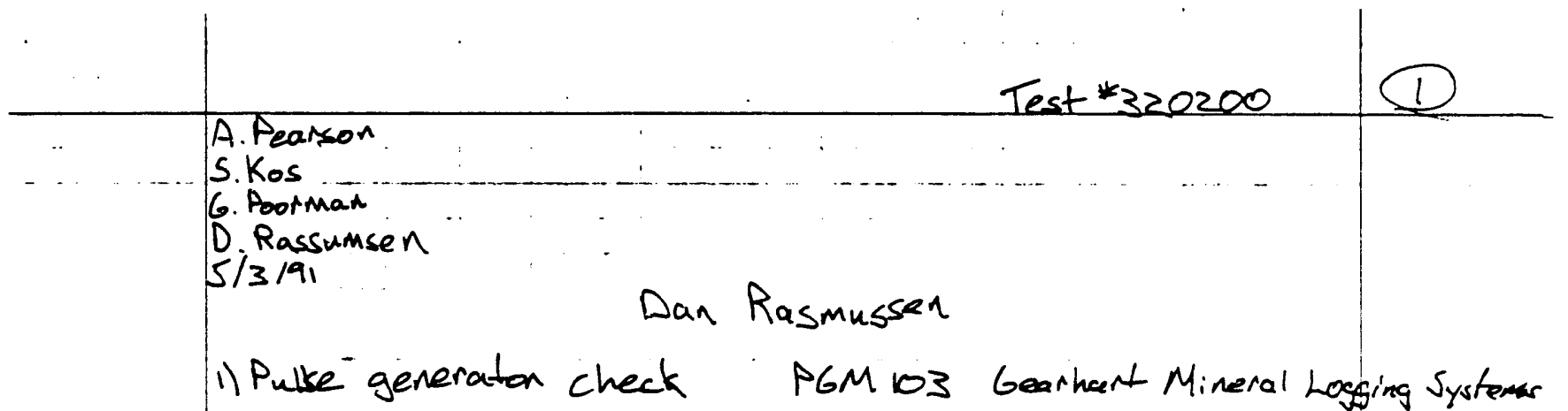
Varialle complitude + output ES.
$50 \mathrm{kH} .5 \mathrm{~V}$ Poak
- output F.S.
$-2.6 \mathrm{~V}$ Peak

Othar ranges + outpent F.S. $>3.0$ Volts

- output Fs. >2.0 Volts

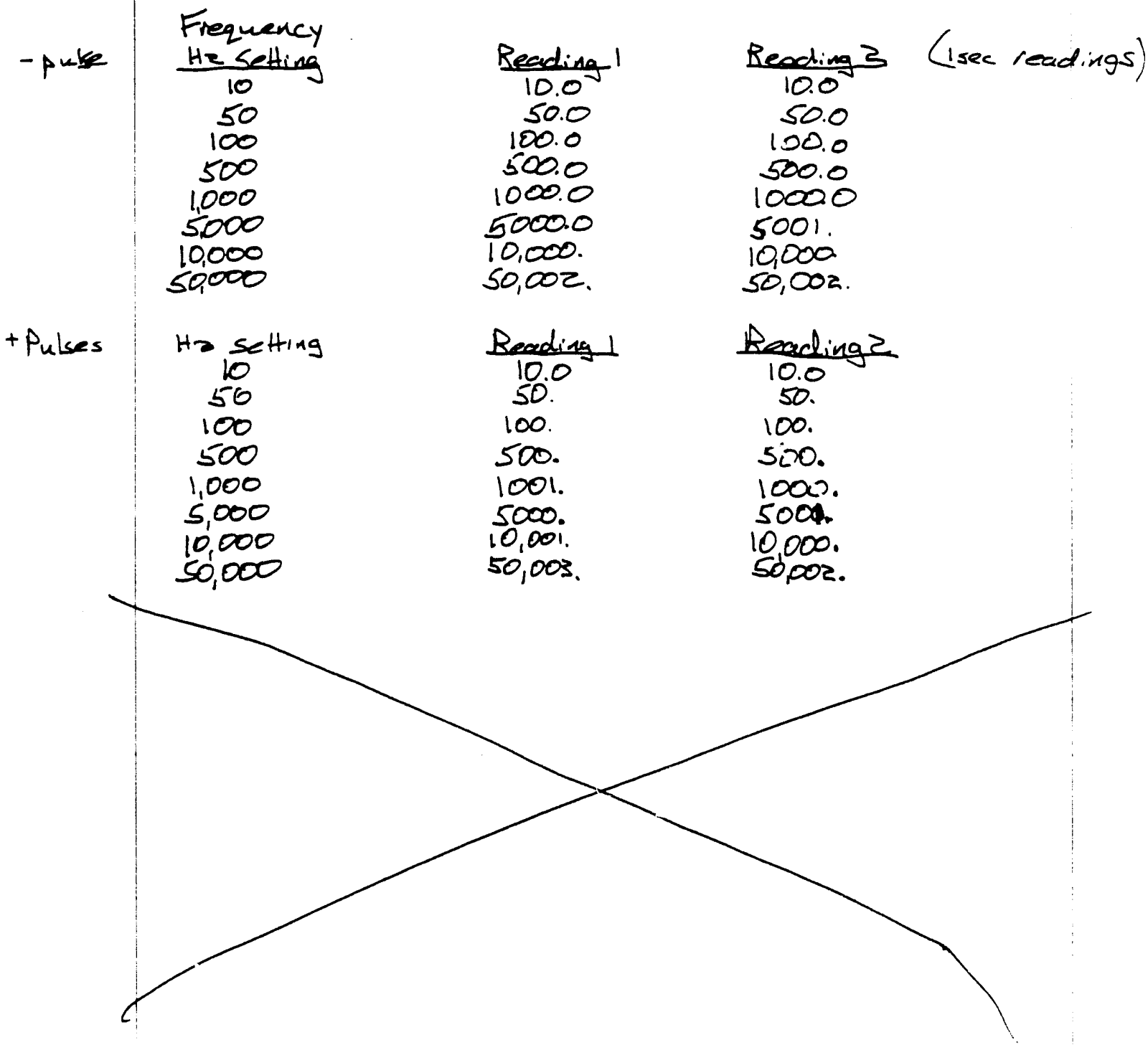

A. 1 


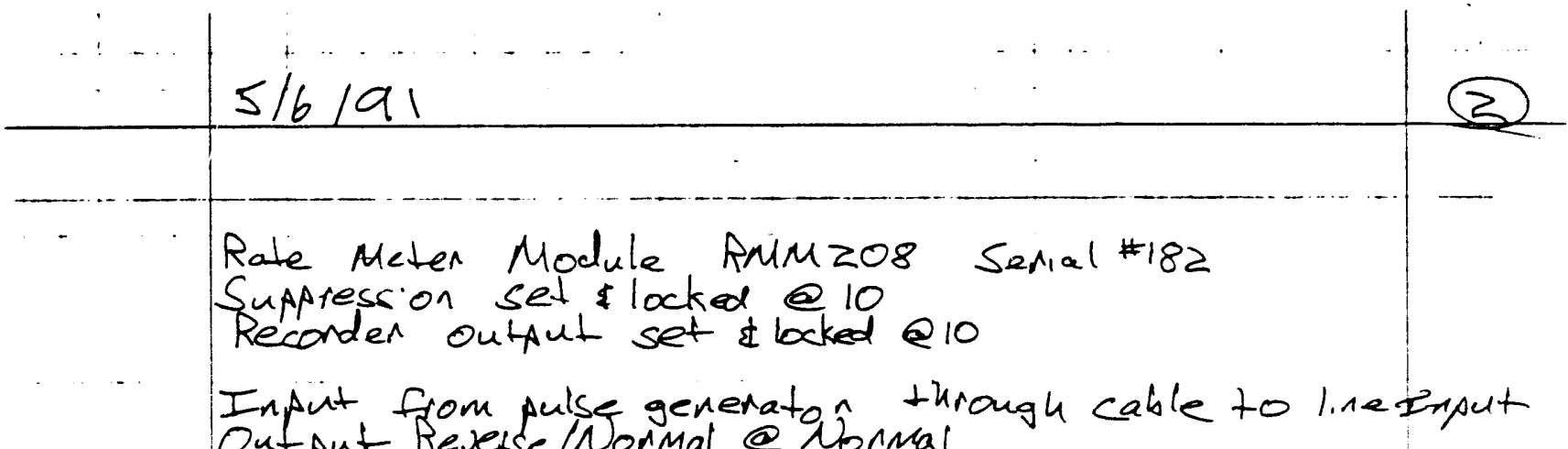

Output ResesselNormal @ Normal Negative Input

Time Consfant $=1 \mathrm{sec}$. Chart Recorder $\$ A \rightarrow \triangle$ conver $D$ iveorecter

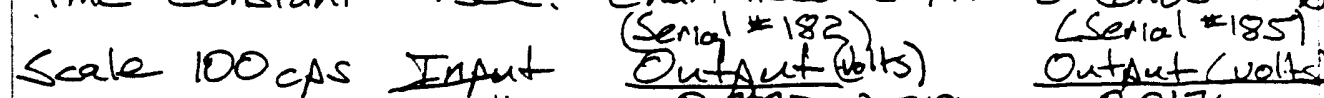

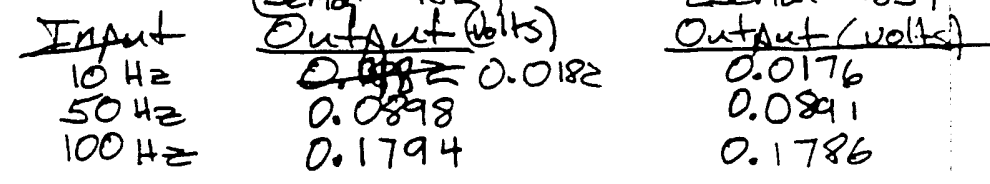

$\begin{array}{lll}\text { Scale } 500 \mathrm{cAs} \quad 100 \mathrm{~Hz} & 0.0362 \\ 500 \mathrm{~Hz} & 0.1796\end{array}$

0.0356

Scate 1000 CAS $100 \mathrm{~Hz} 0.0183$

0.1786

$\begin{array}{ll}500 \mathrm{~Hz} & 0.0900 \\ 1000 \mathrm{~Hz} & 0.1799\end{array}$

0.0178

0.0893

0.1789

Scale 5,000 cas $500 \mathrm{~Hz} \quad 0.0182$

0.0178

$1000 \mathrm{~Hz}-0.0362$

0.0357

0.1789

Scale $10,000 \mathrm{cps} 1000 \mathrm{~Hz} 0.0183$

0.0179

$\begin{array}{rl}5,000 \mathrm{~Hz} & 0.0900 \\ 10,000 \mathrm{~Hz} & 0.1799\end{array}$

0.0894

0.1789

Scale 50,000 cas 5,000 $\mathrm{Hz} 0.0183$

0.0178

10,000 Hz 0.0362
$50,000 \mathrm{~Hz} 0.1799$

0.0357

0.1790

Intermal Oscillaton $100 \mathrm{~Hz} \quad \operatorname{l00}_{\text {a AS } 0.1798}$

0.1791

1000 cps 0.0364

0.0360

Chart Reconder Calibration

3

Internal cascillion on Rate meten

set full seale Reconded on

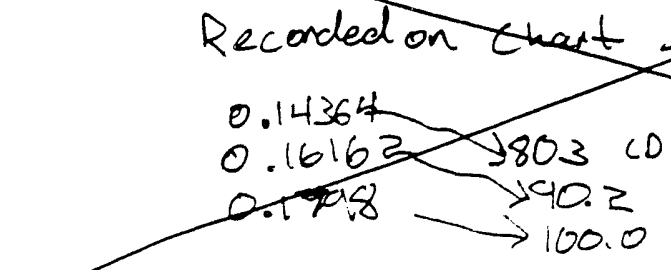

10 divitsons

0.03596 zodivisions

0.0537430 divisions

$0.2717240 " 50.4$

0.10768

0.12566

60.3

A. 2 


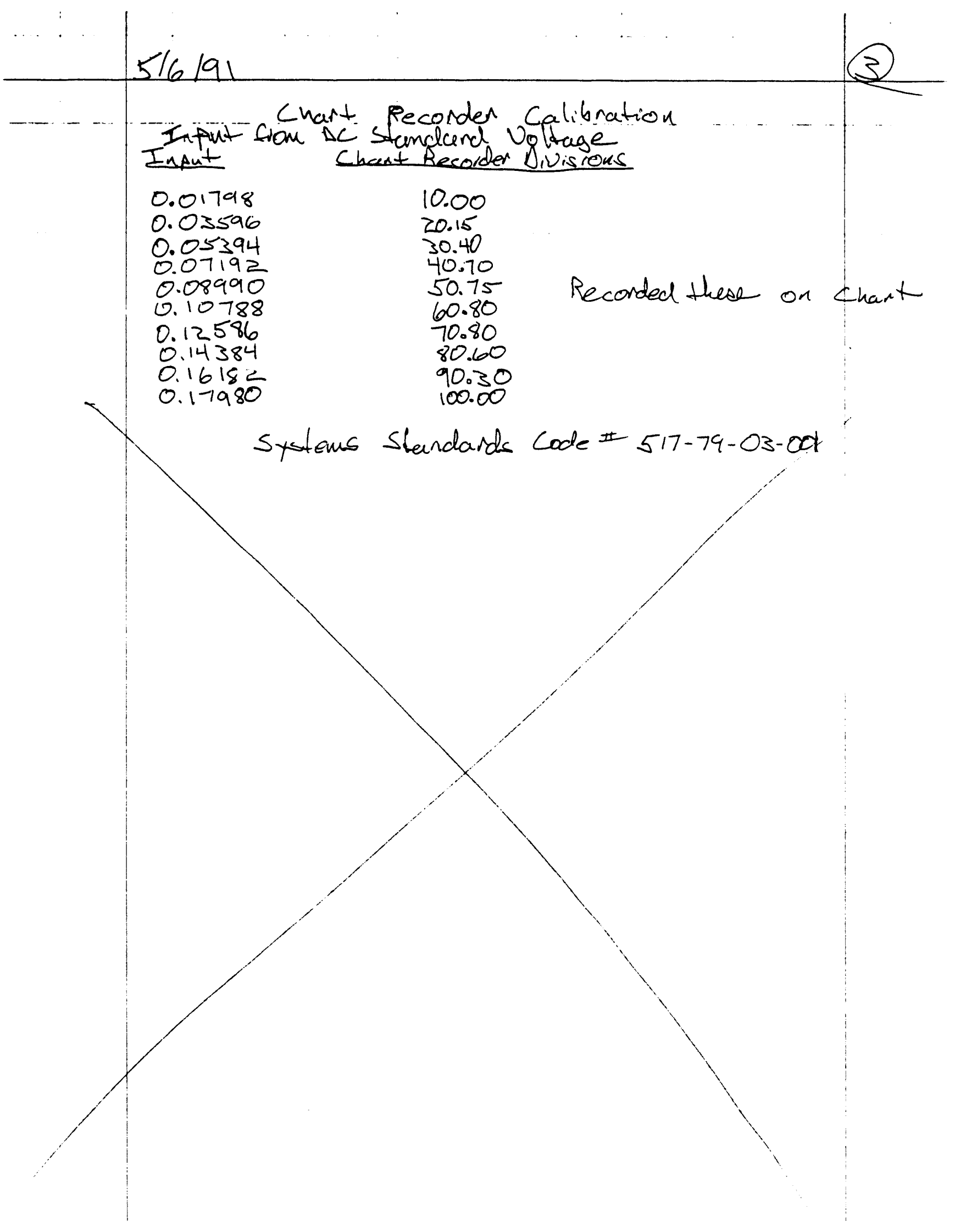

A. 3 


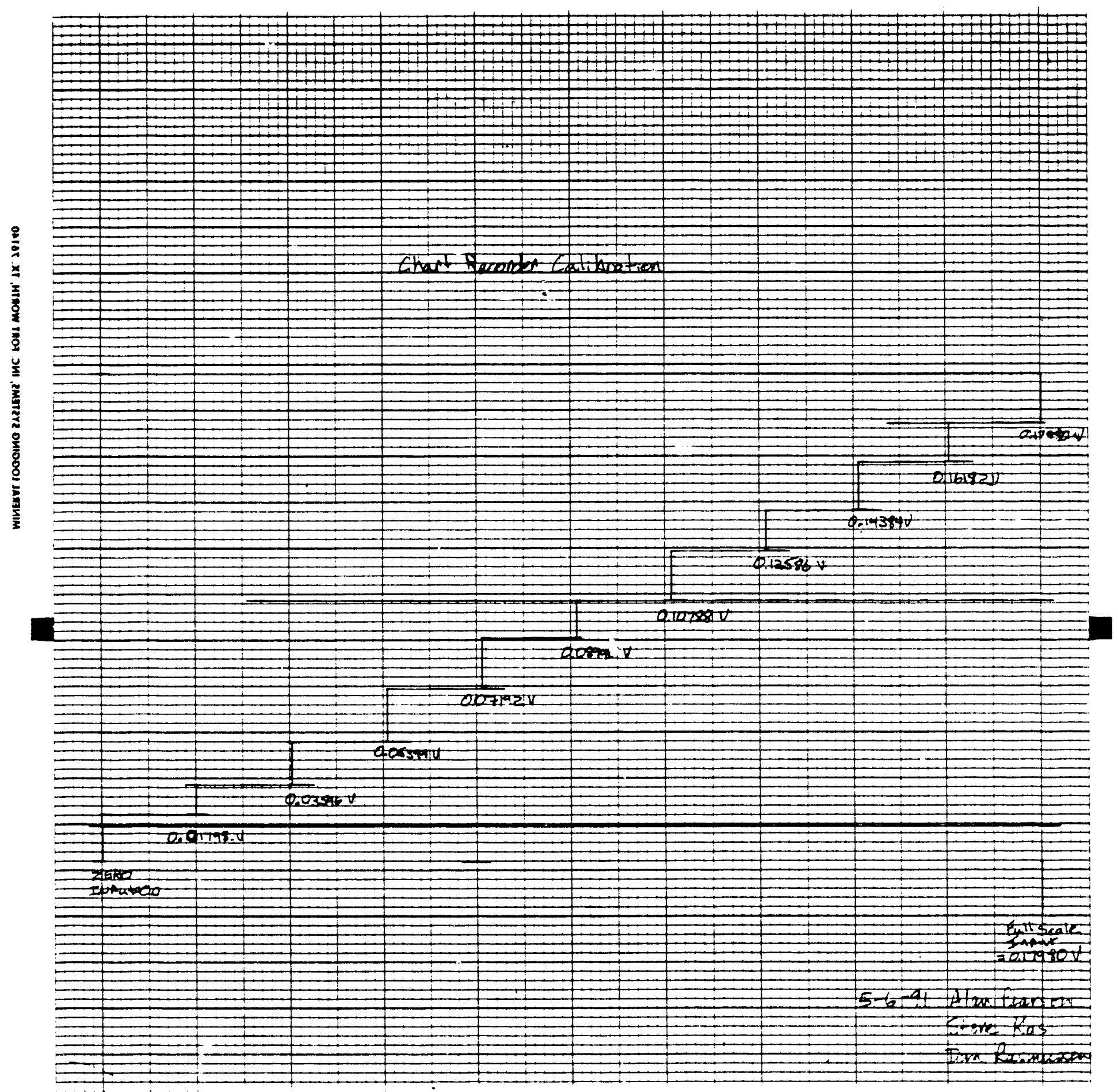




\section{APPENDIX B}

DATA FROM DEAD-TIME DETERMINATION MEASUREMENTS 


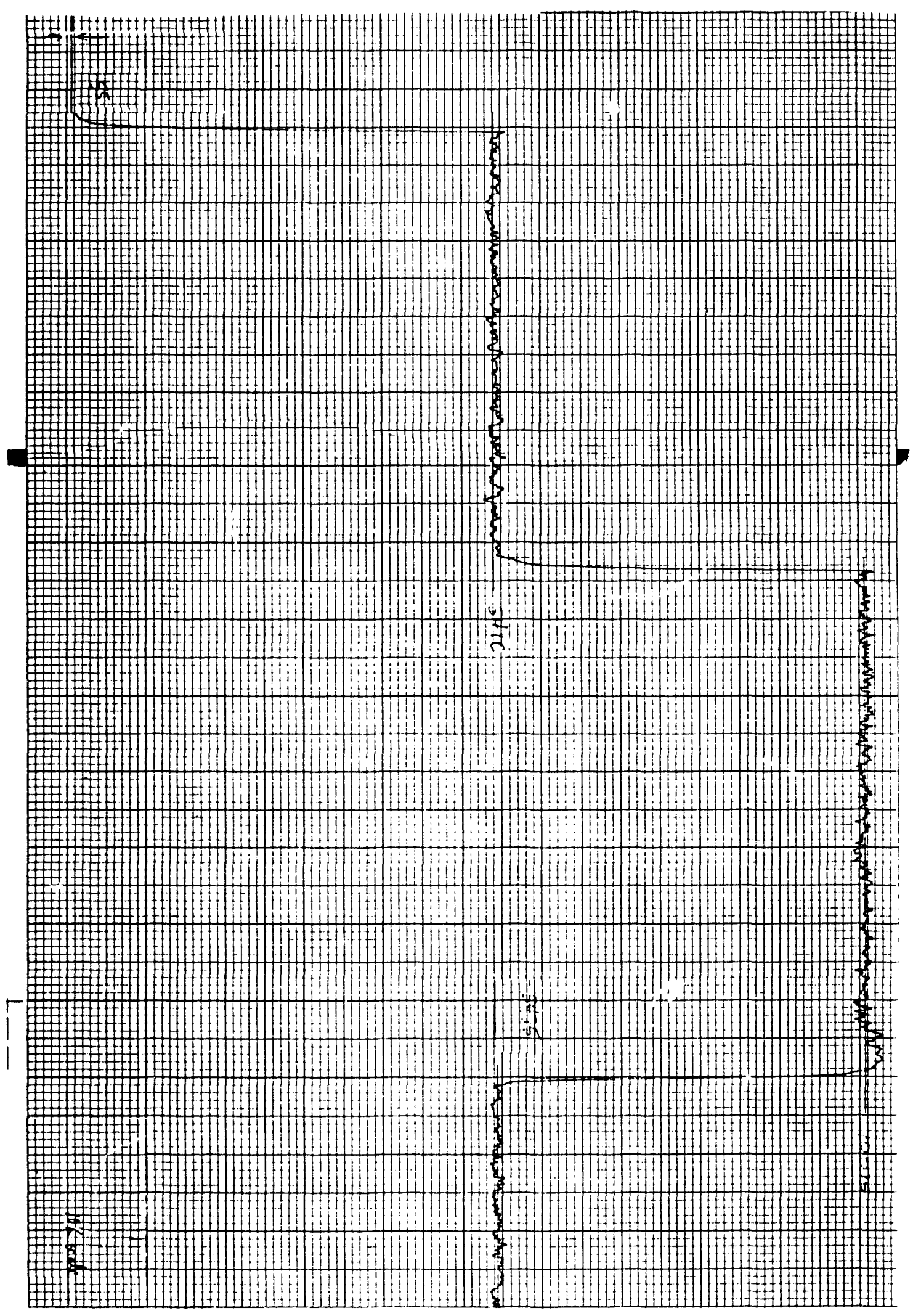

B. 1 


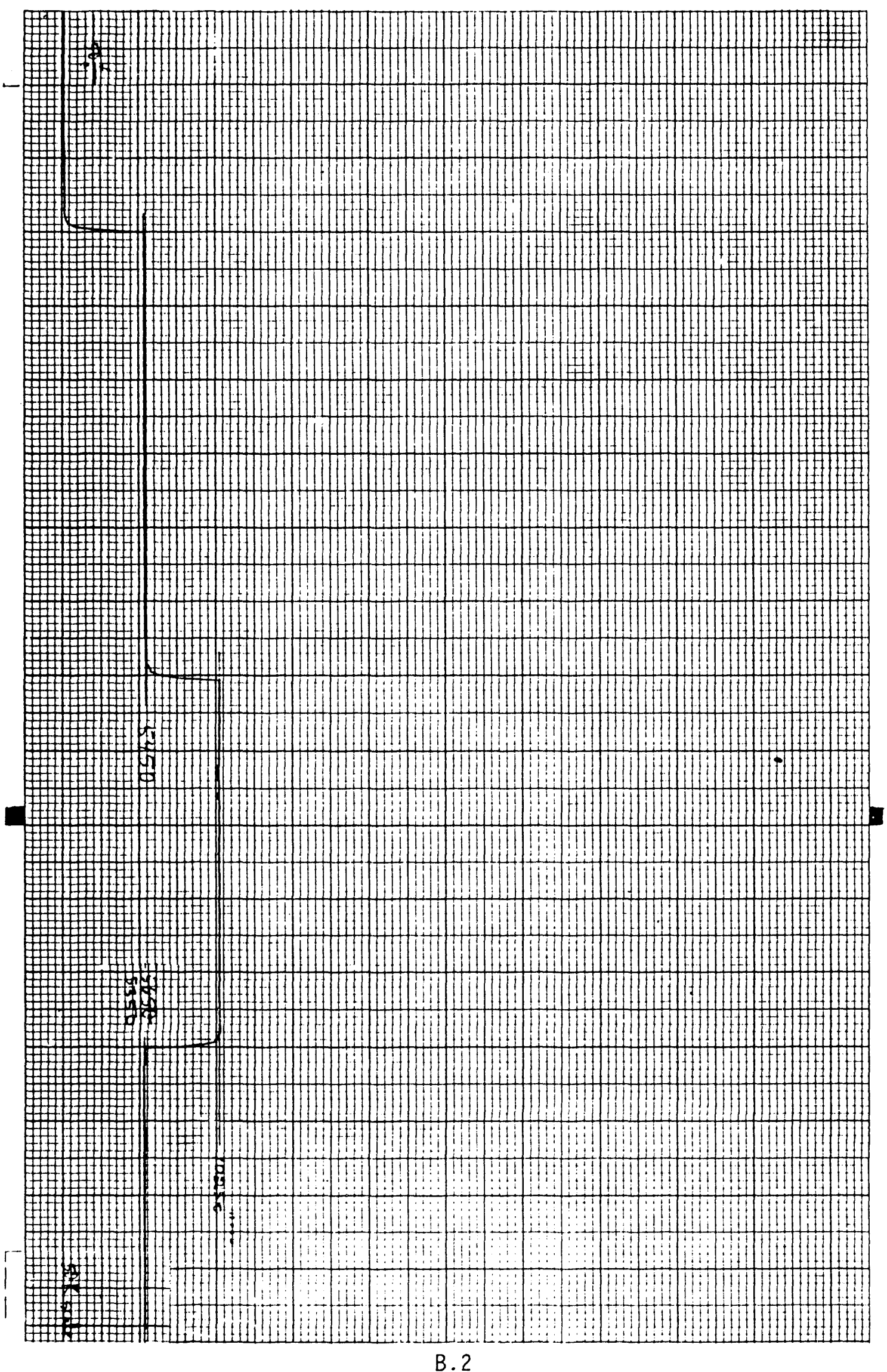




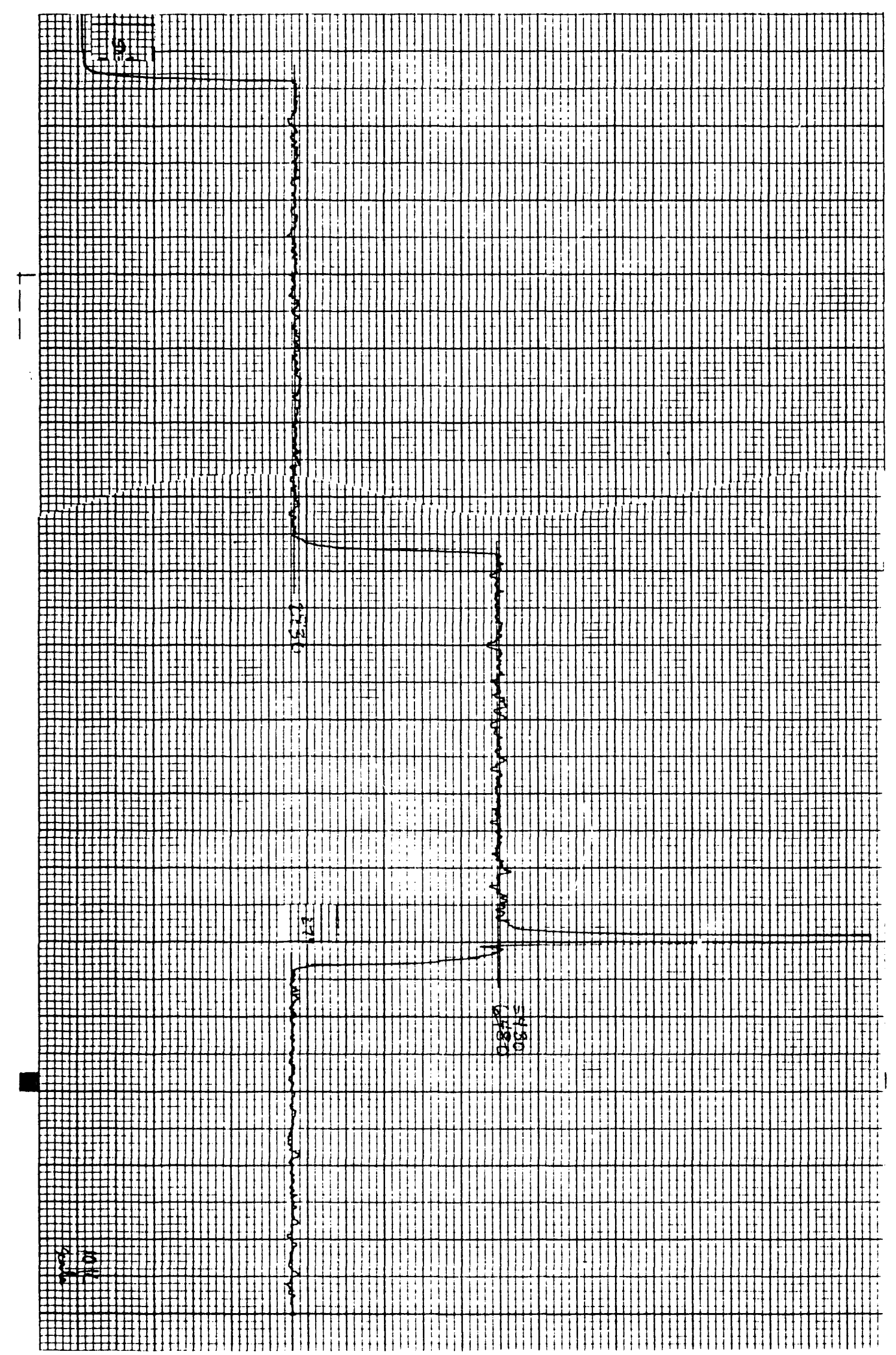

B. 3 


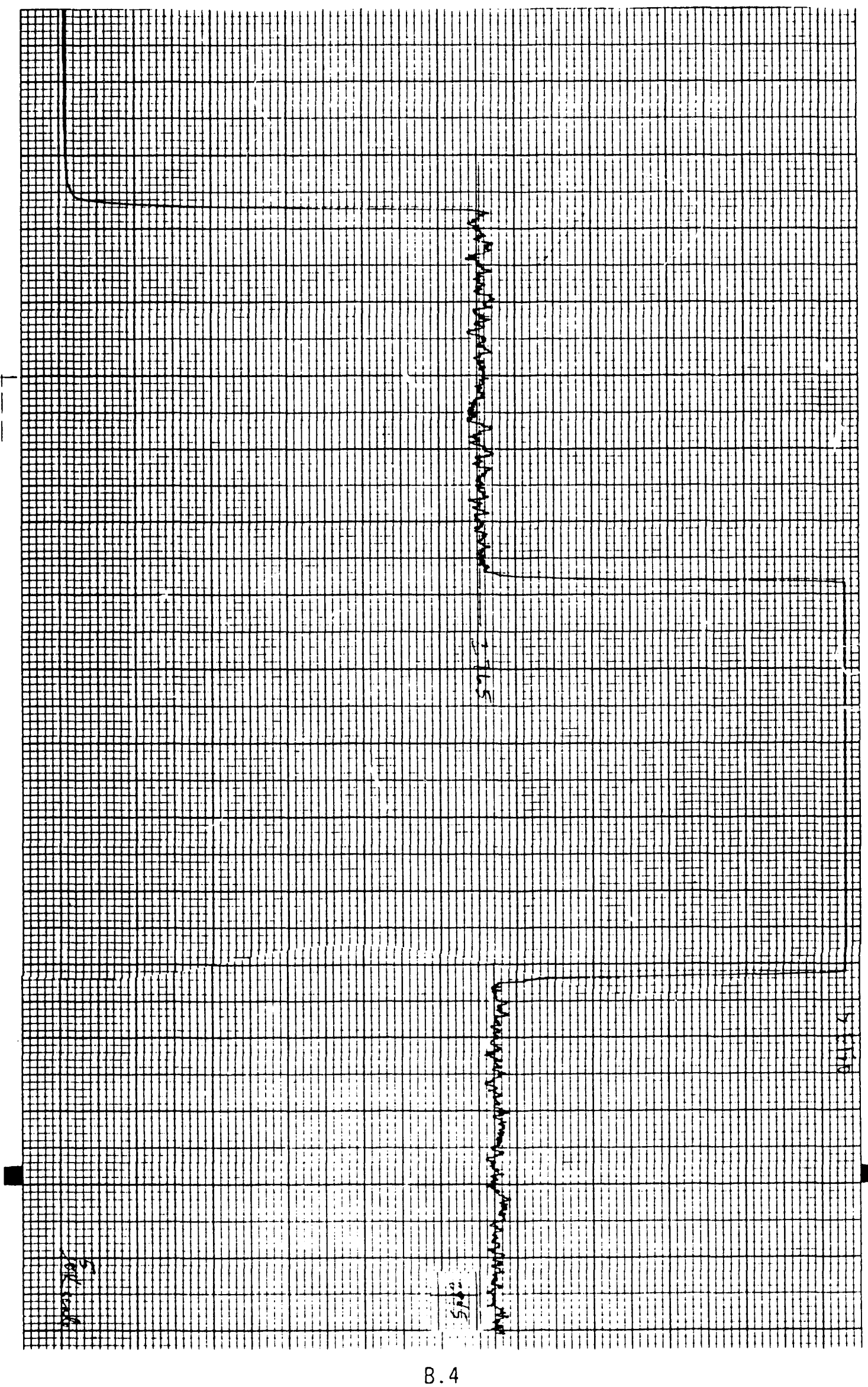




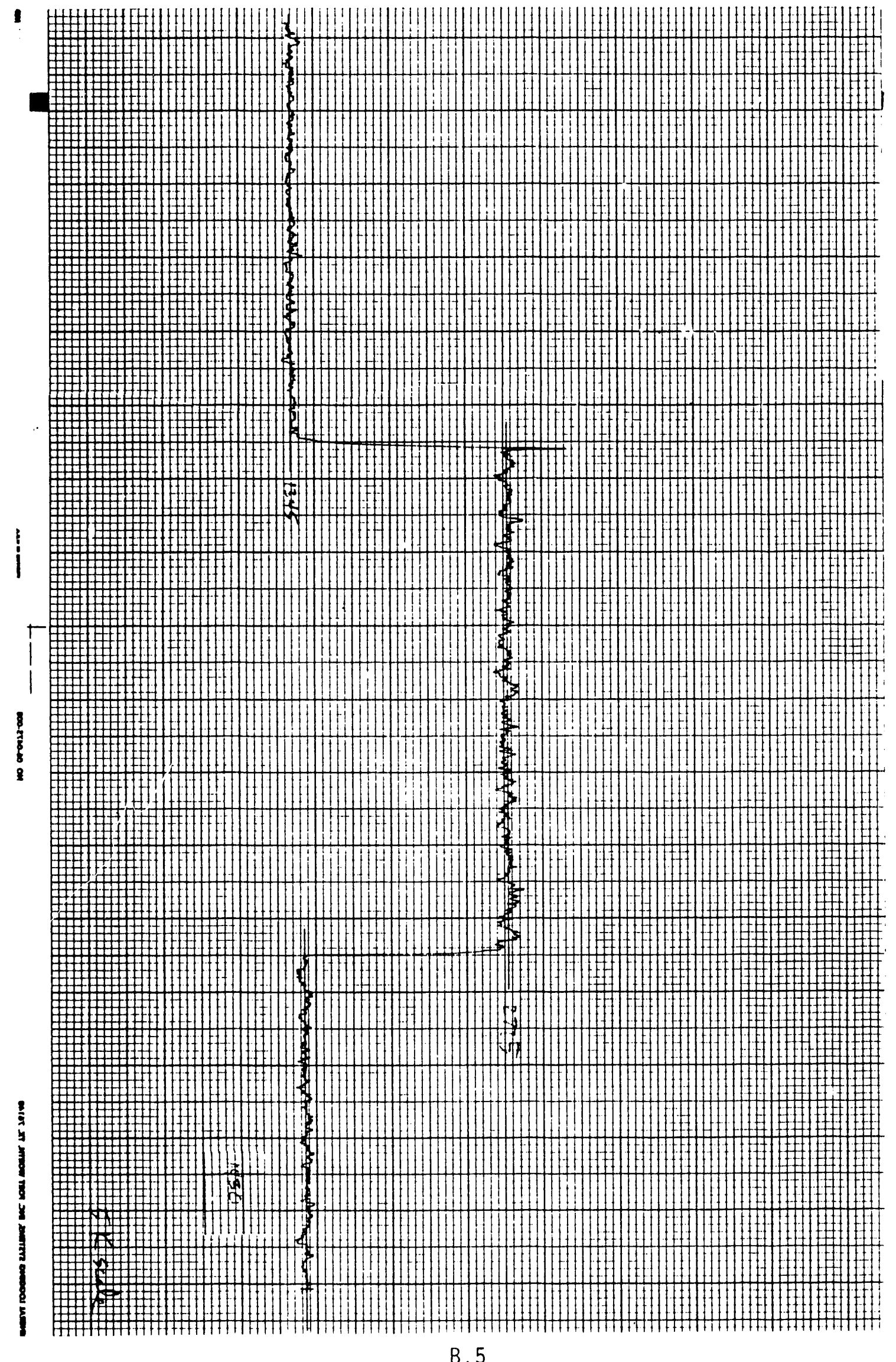




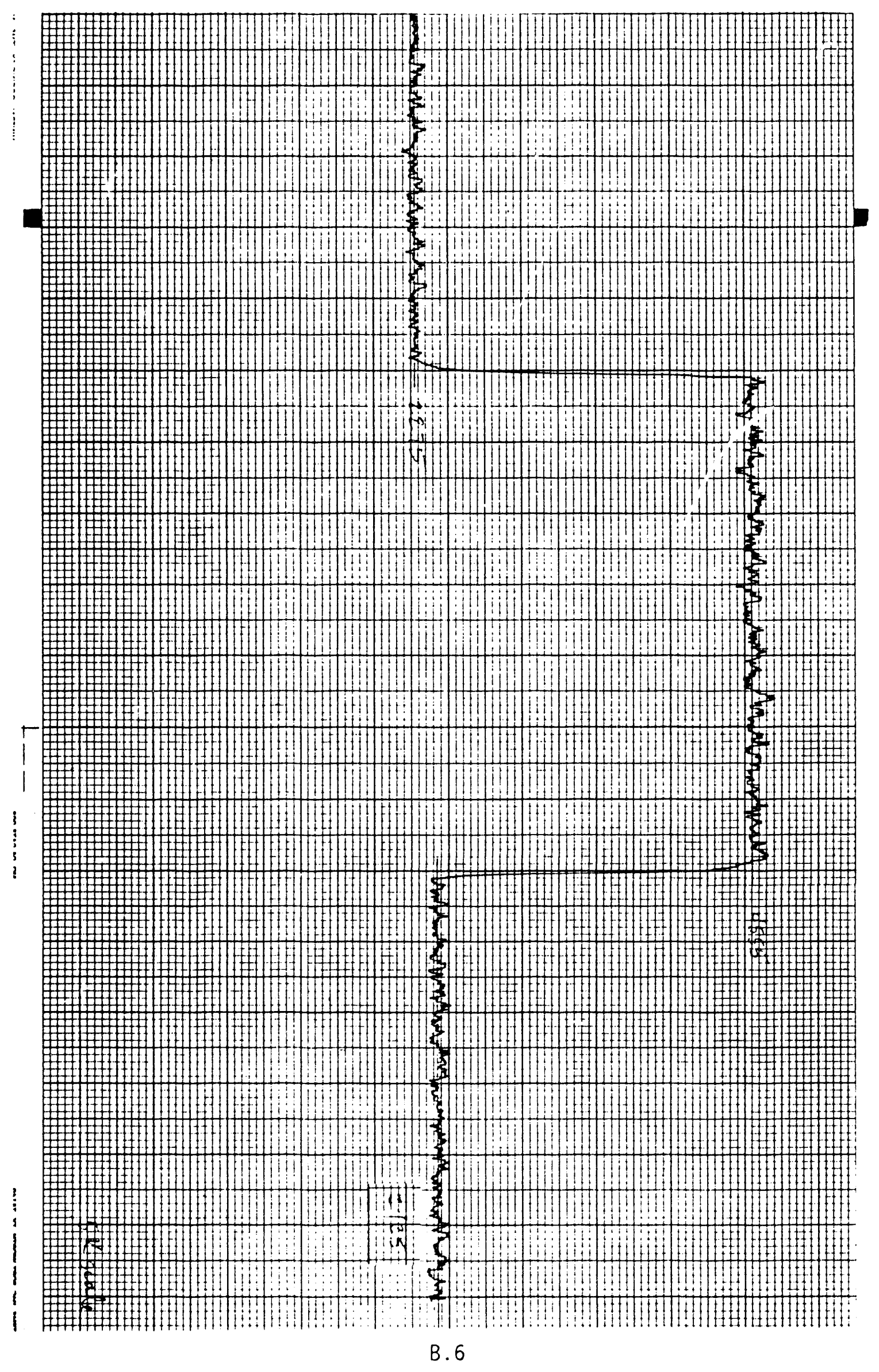


APPENDIX C

DATA FROM PRIMARY CALIBRATION MEASUREMENTS 


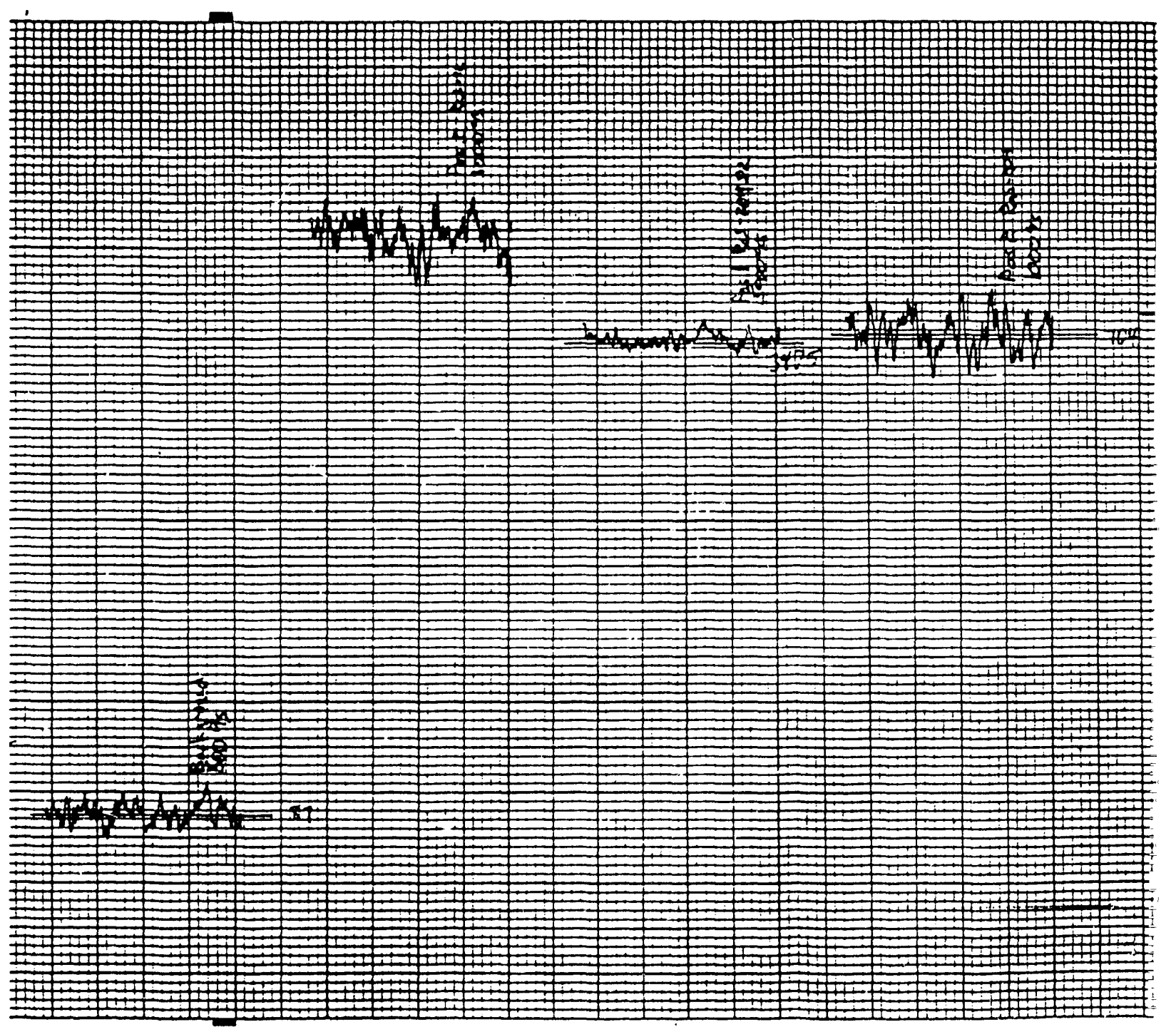




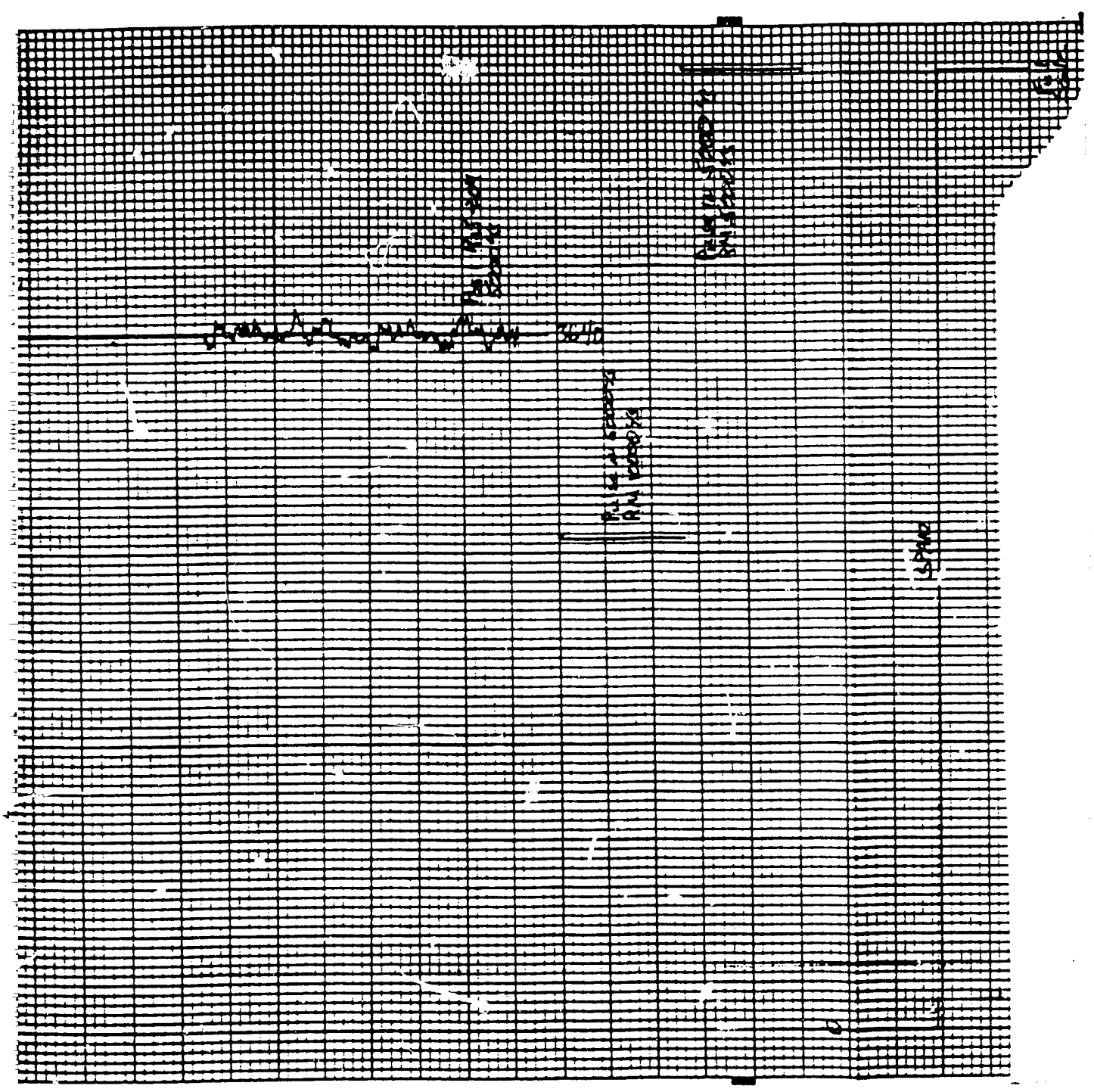

C. 1 


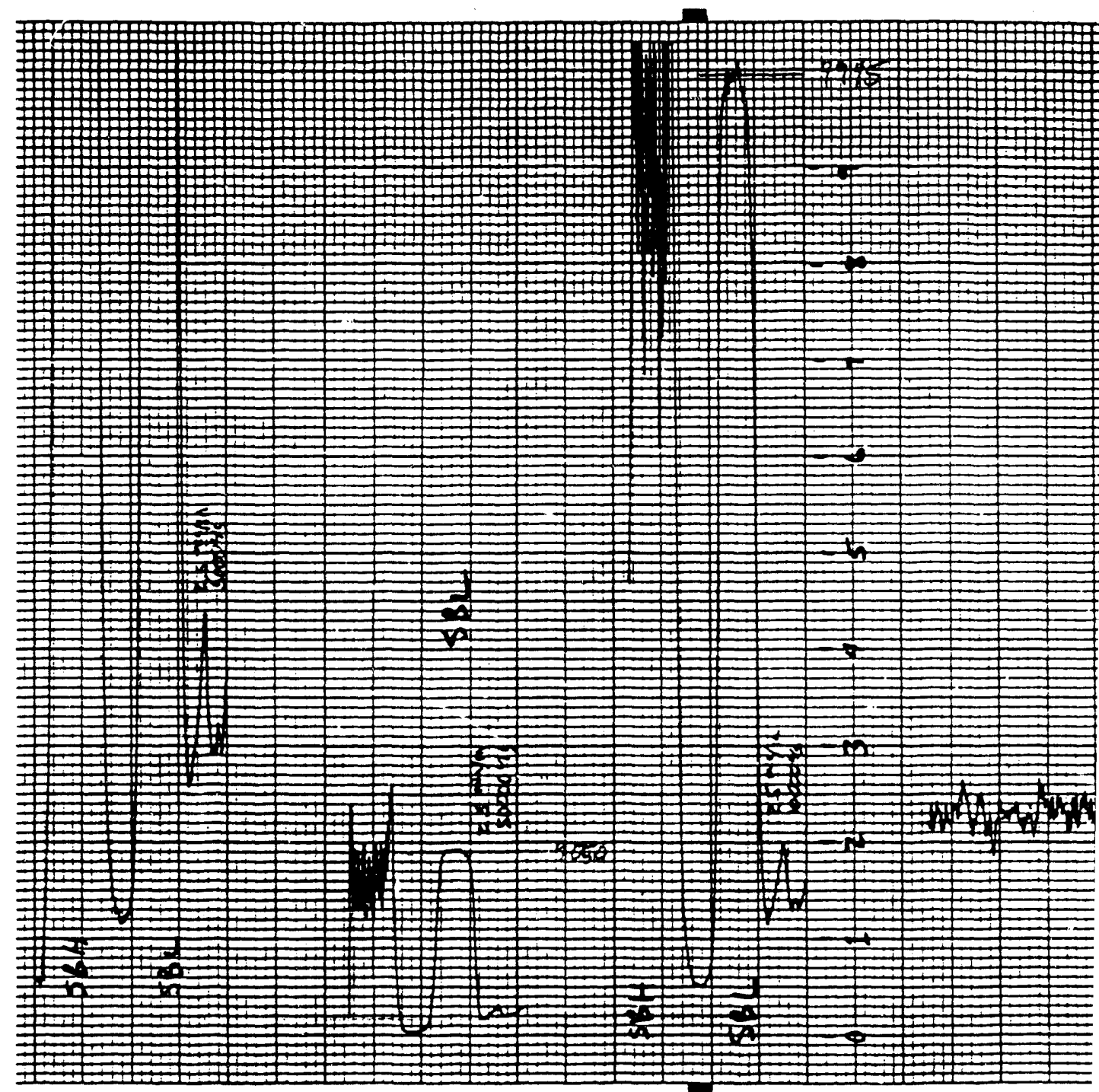




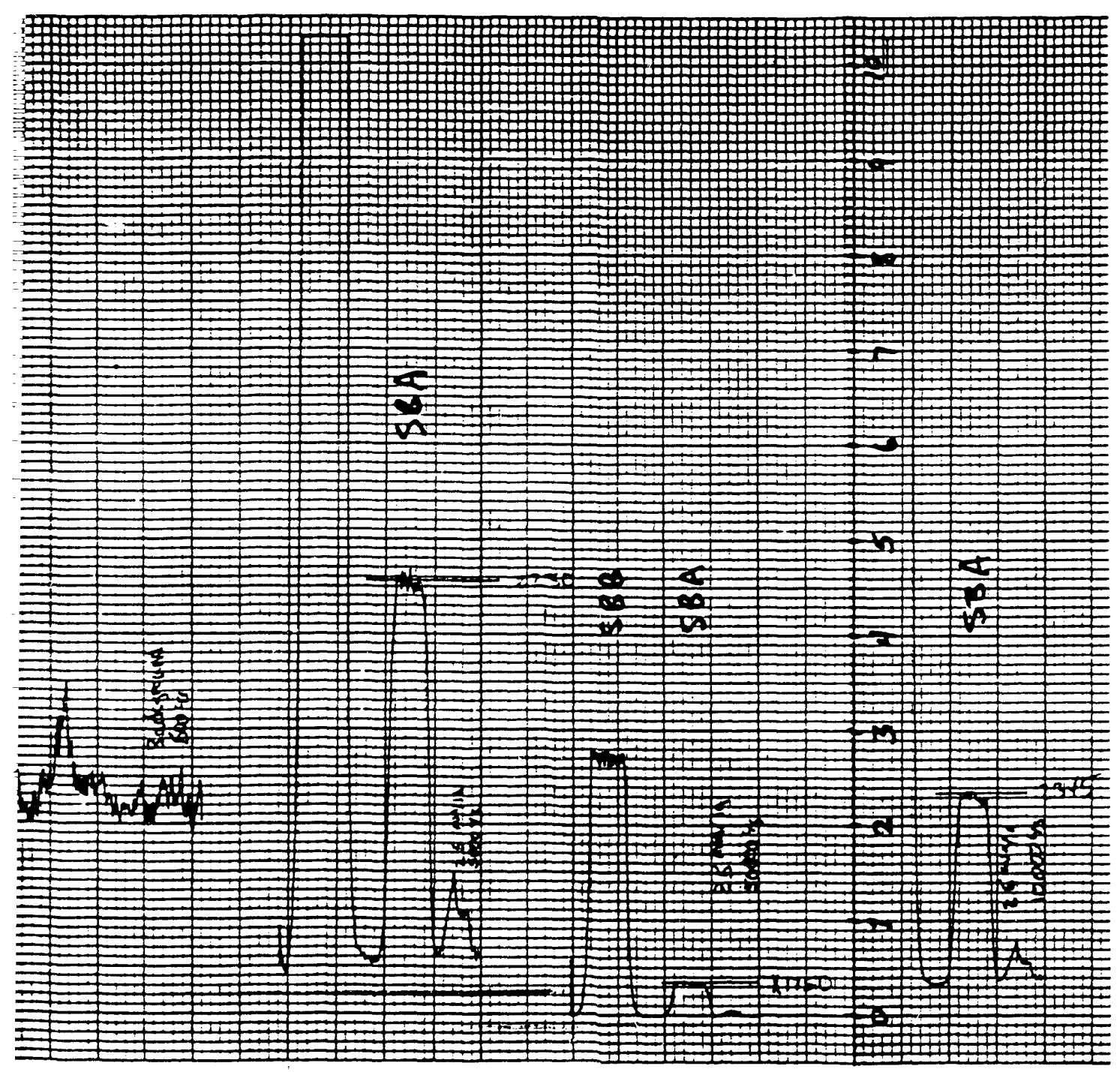

C. 2 


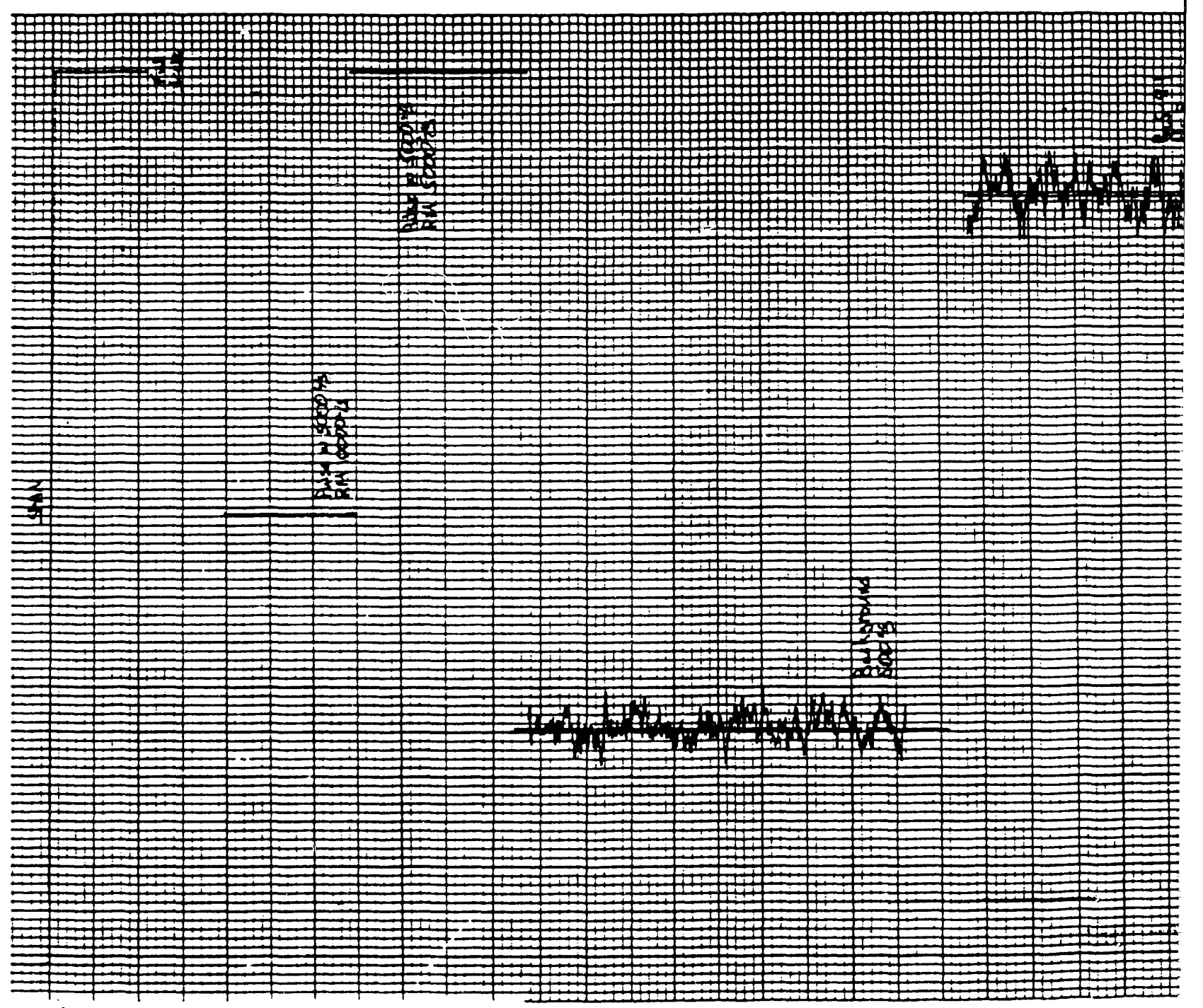




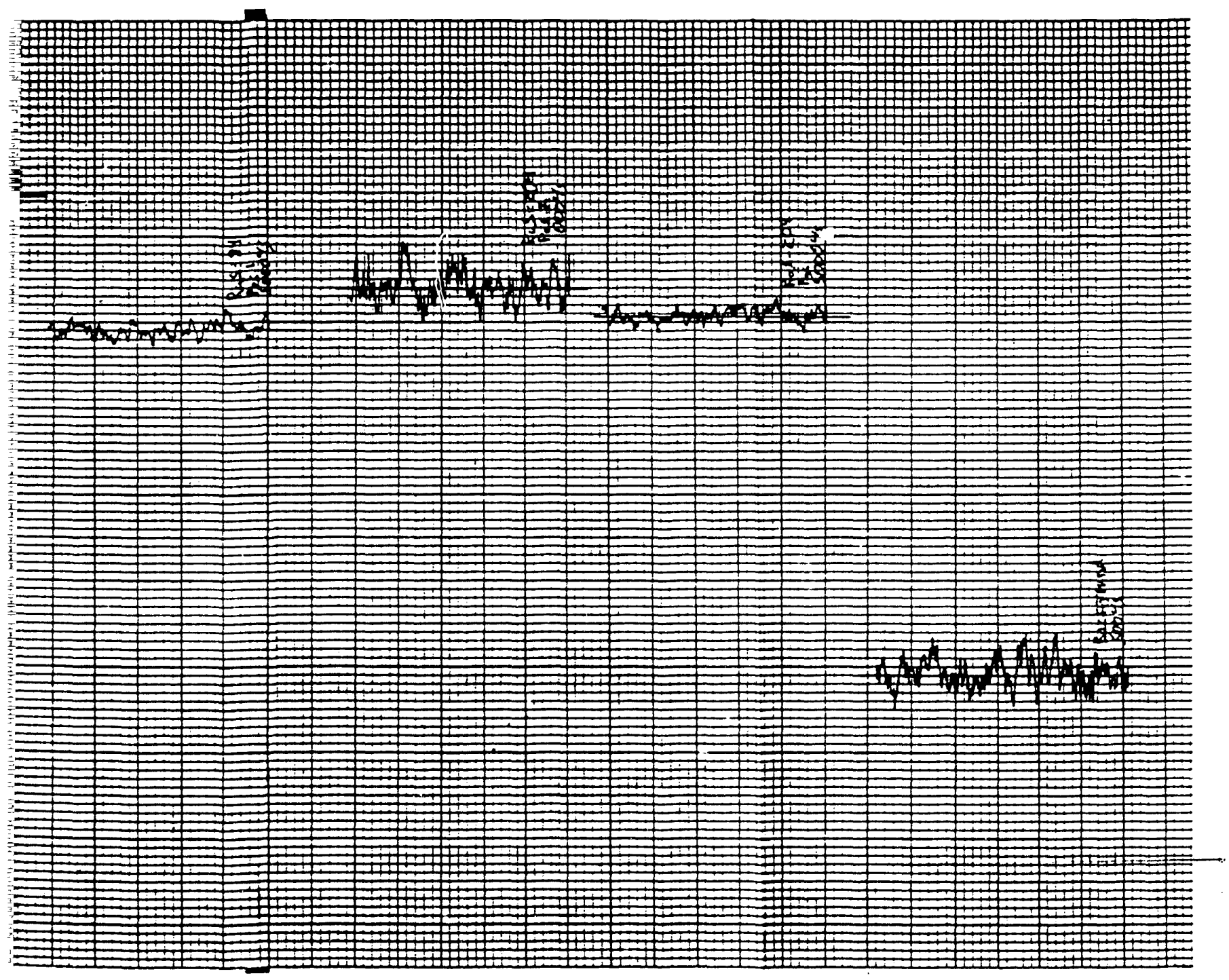

C. 3 
APPENDIX D

DATA FROM FIELD SOURCE CROSS-CALIBRATION MEASUREMENTS 


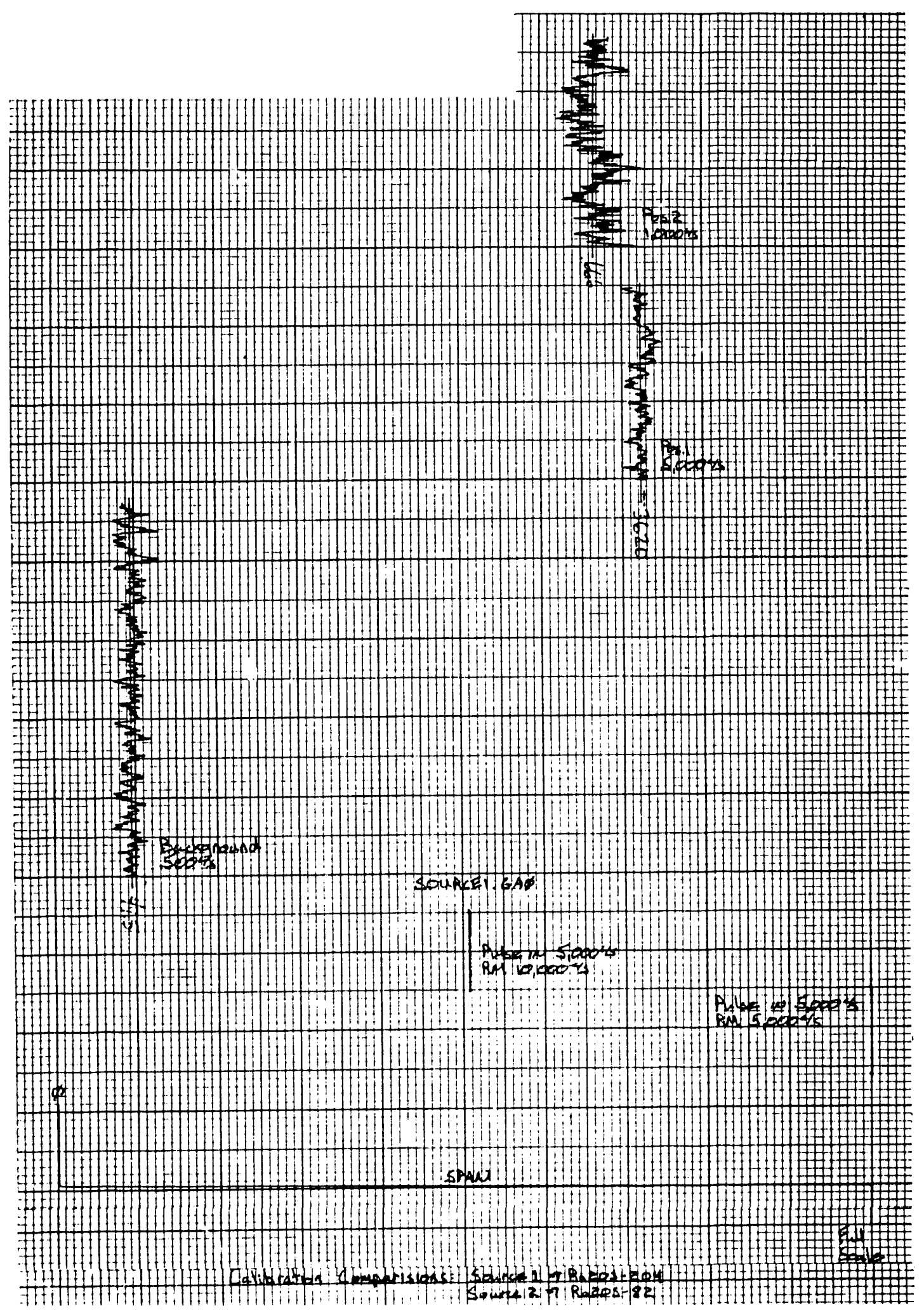

D. 1 


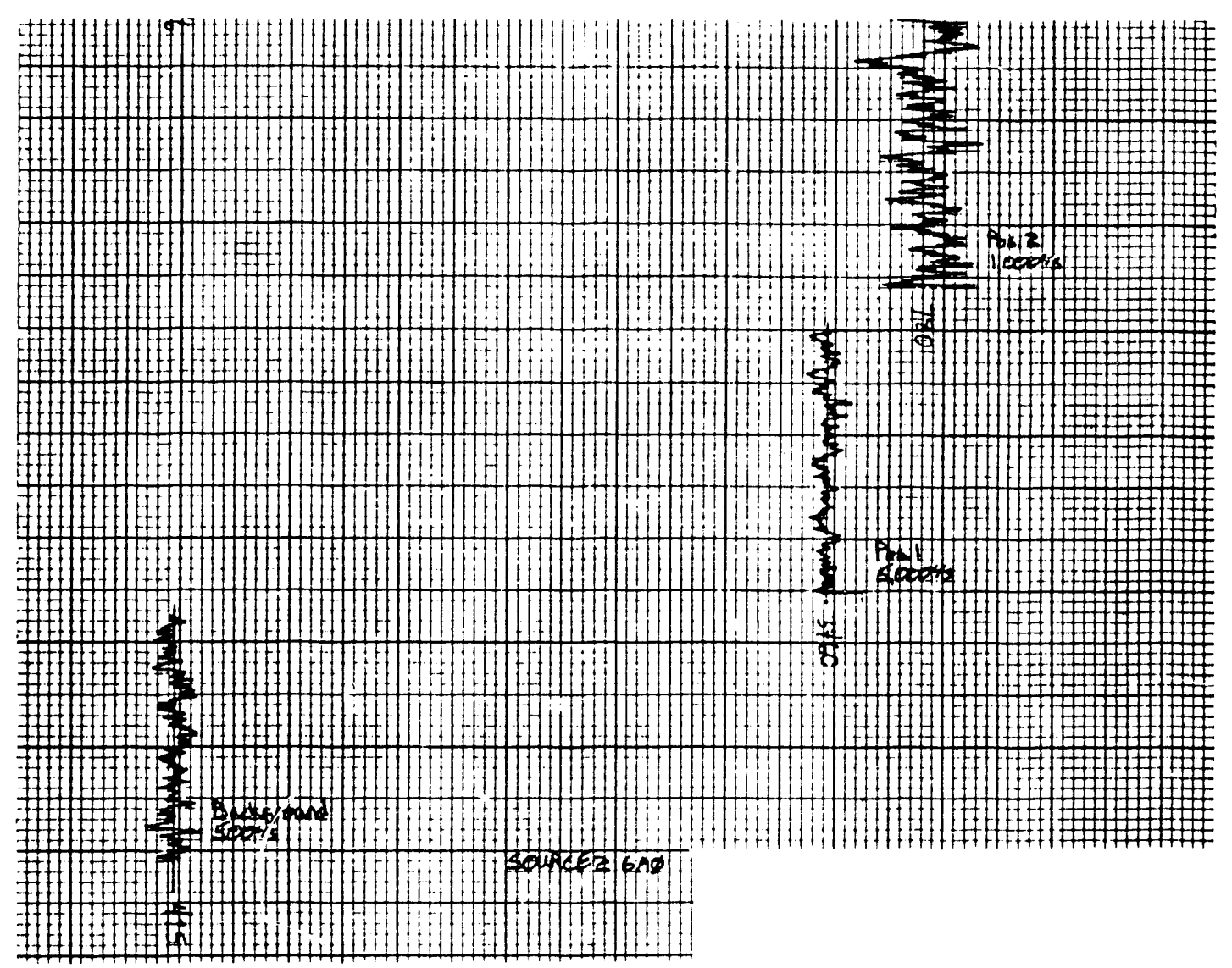

D. 2 


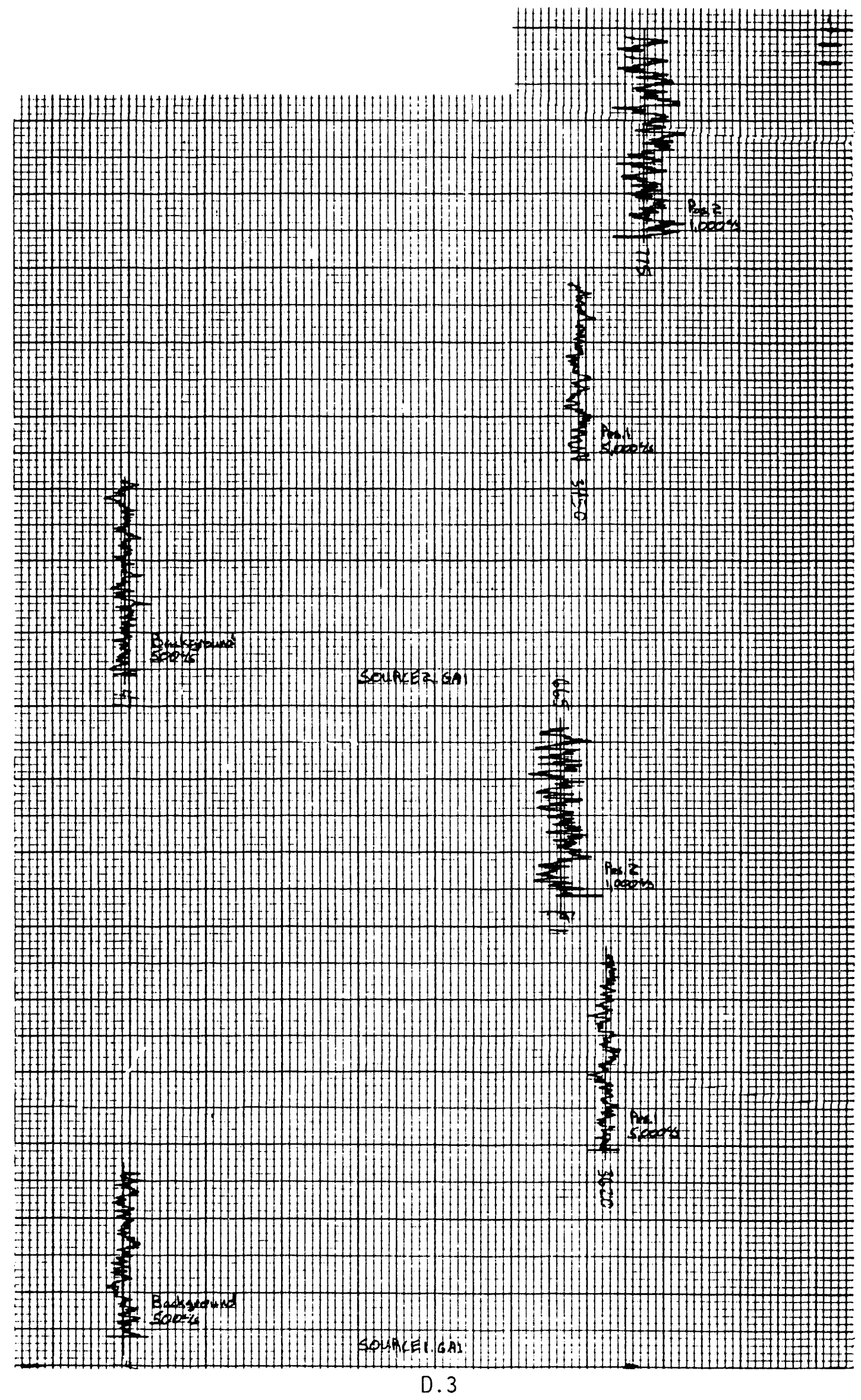




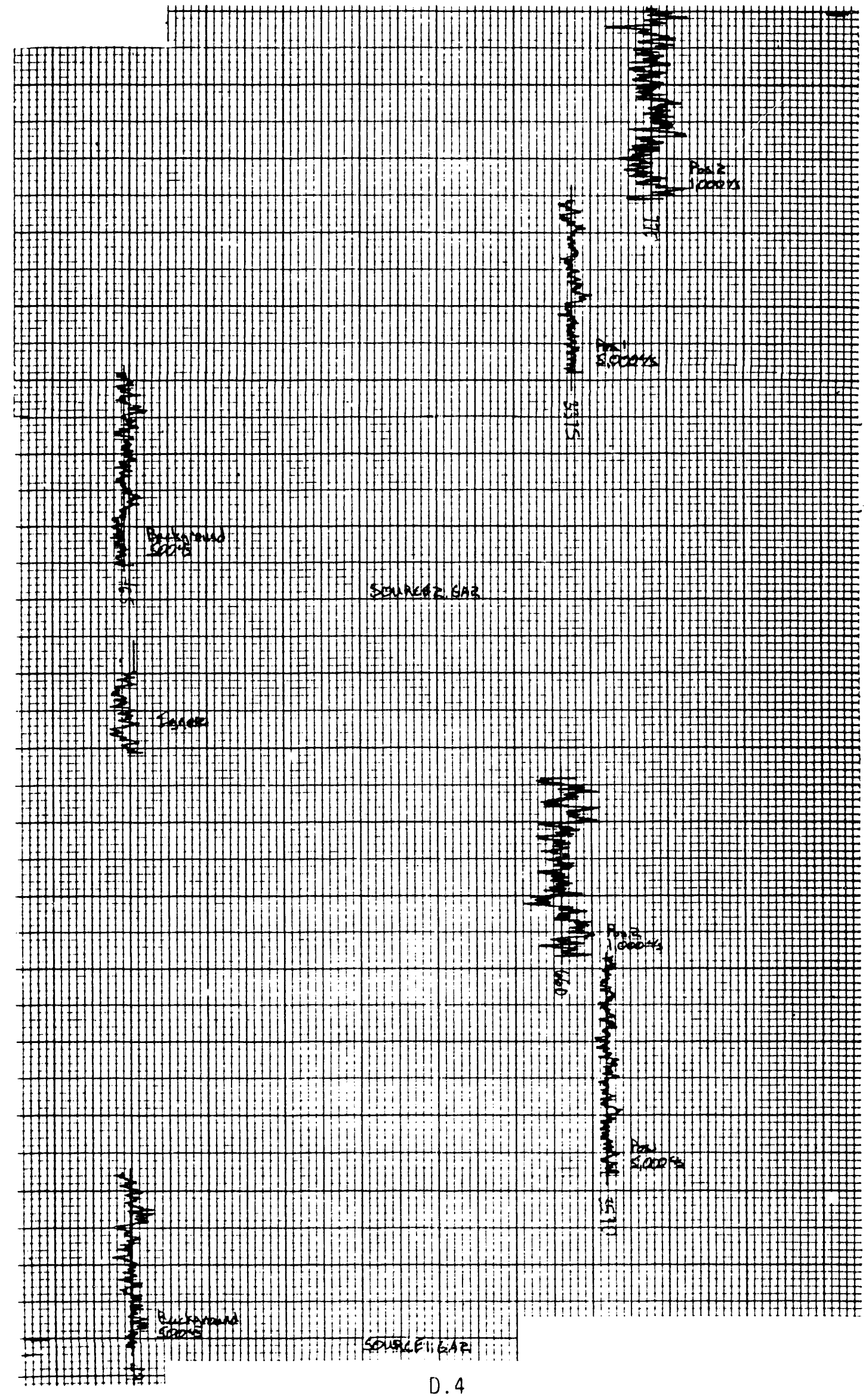




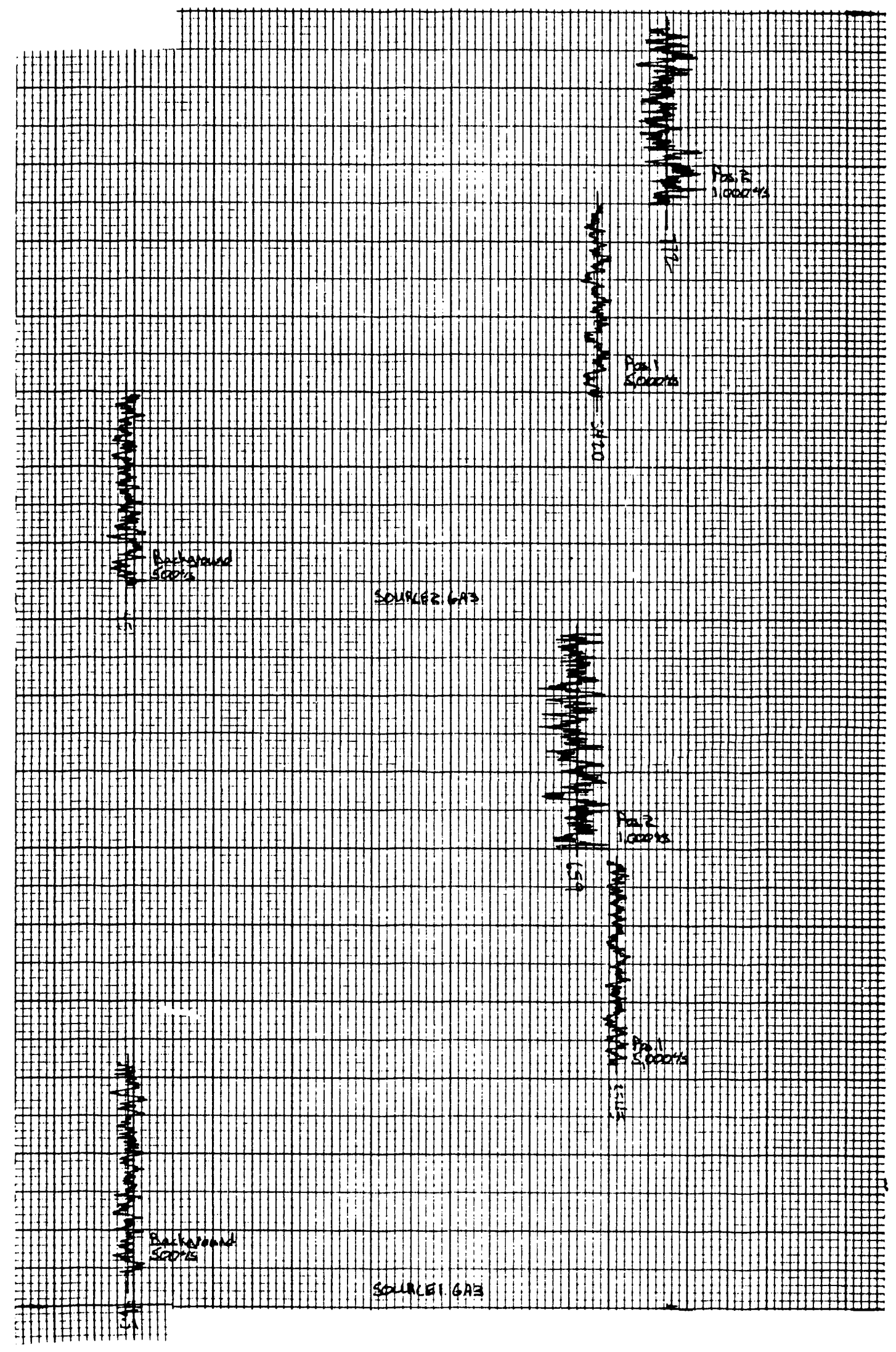

D. 5 


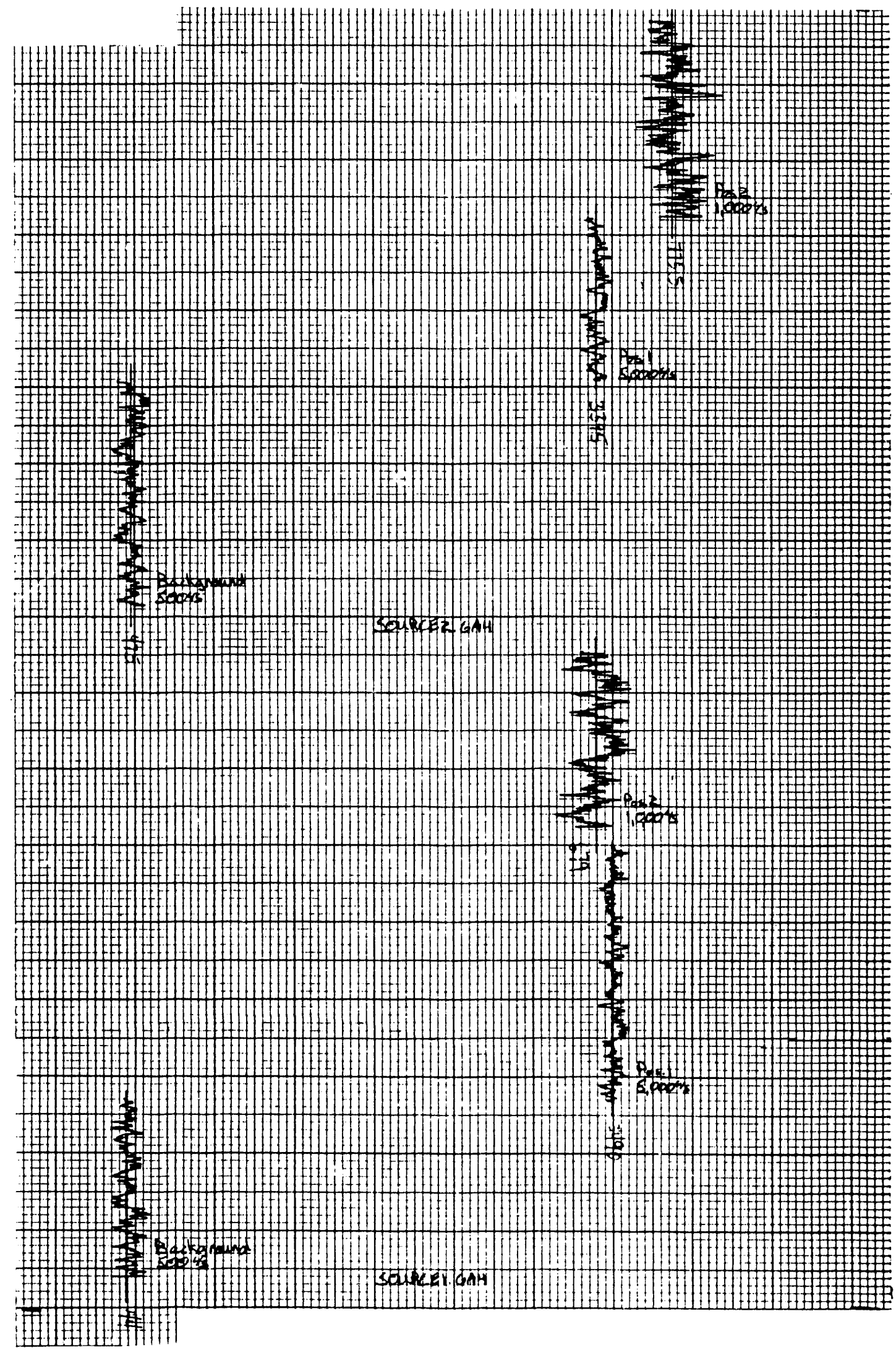

D. 6 


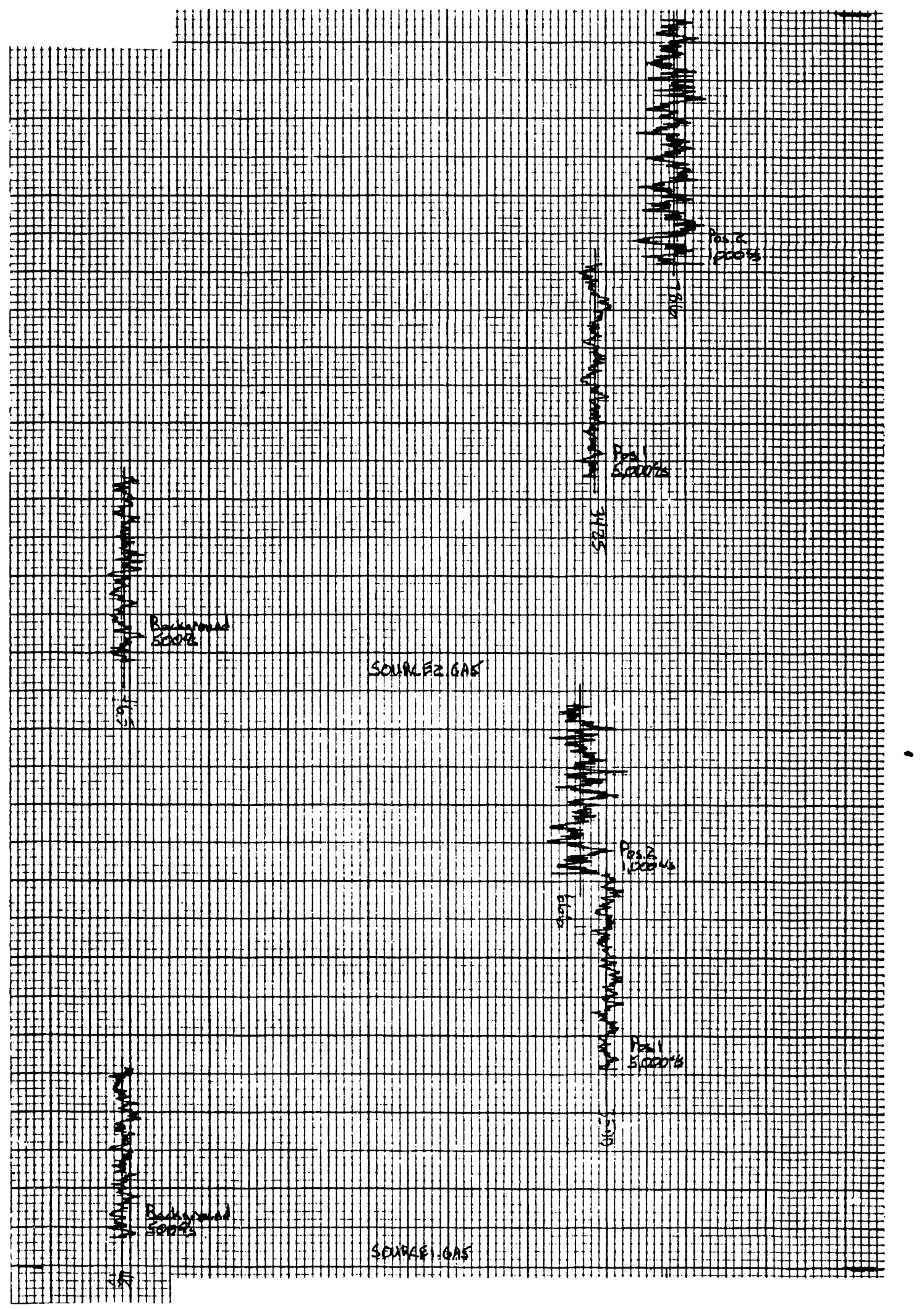

D. 7 


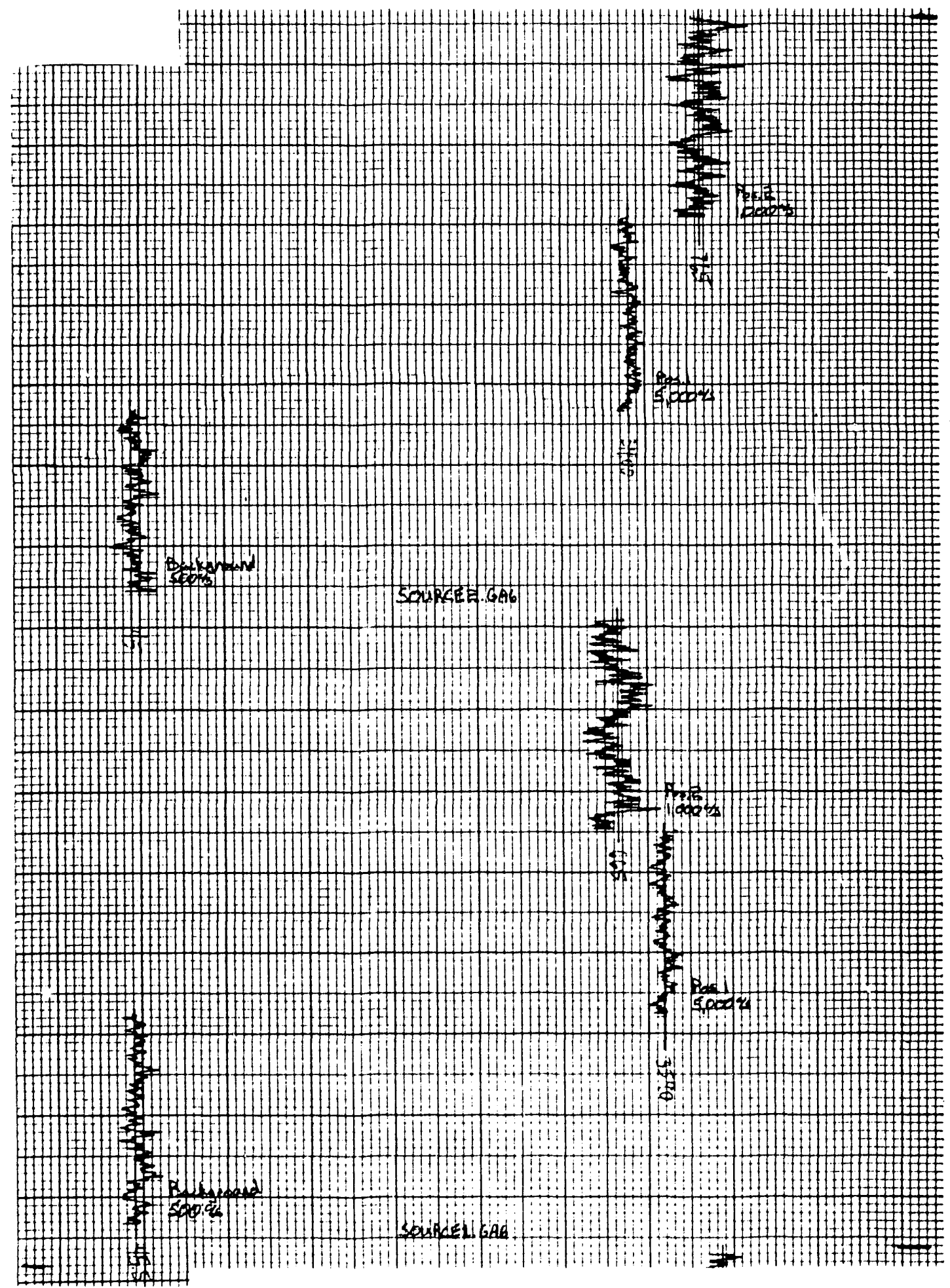

D. 8 


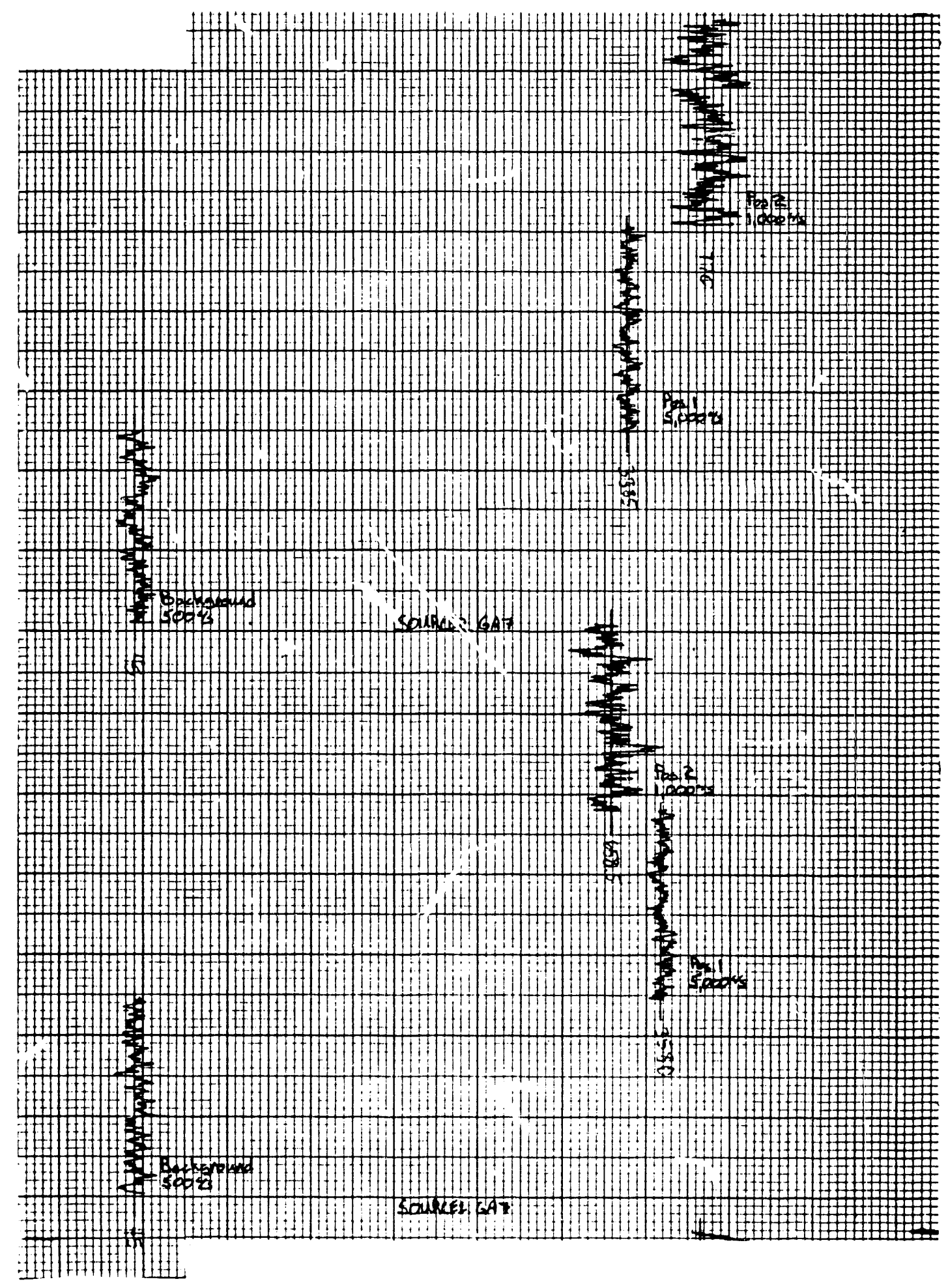

D. 9 


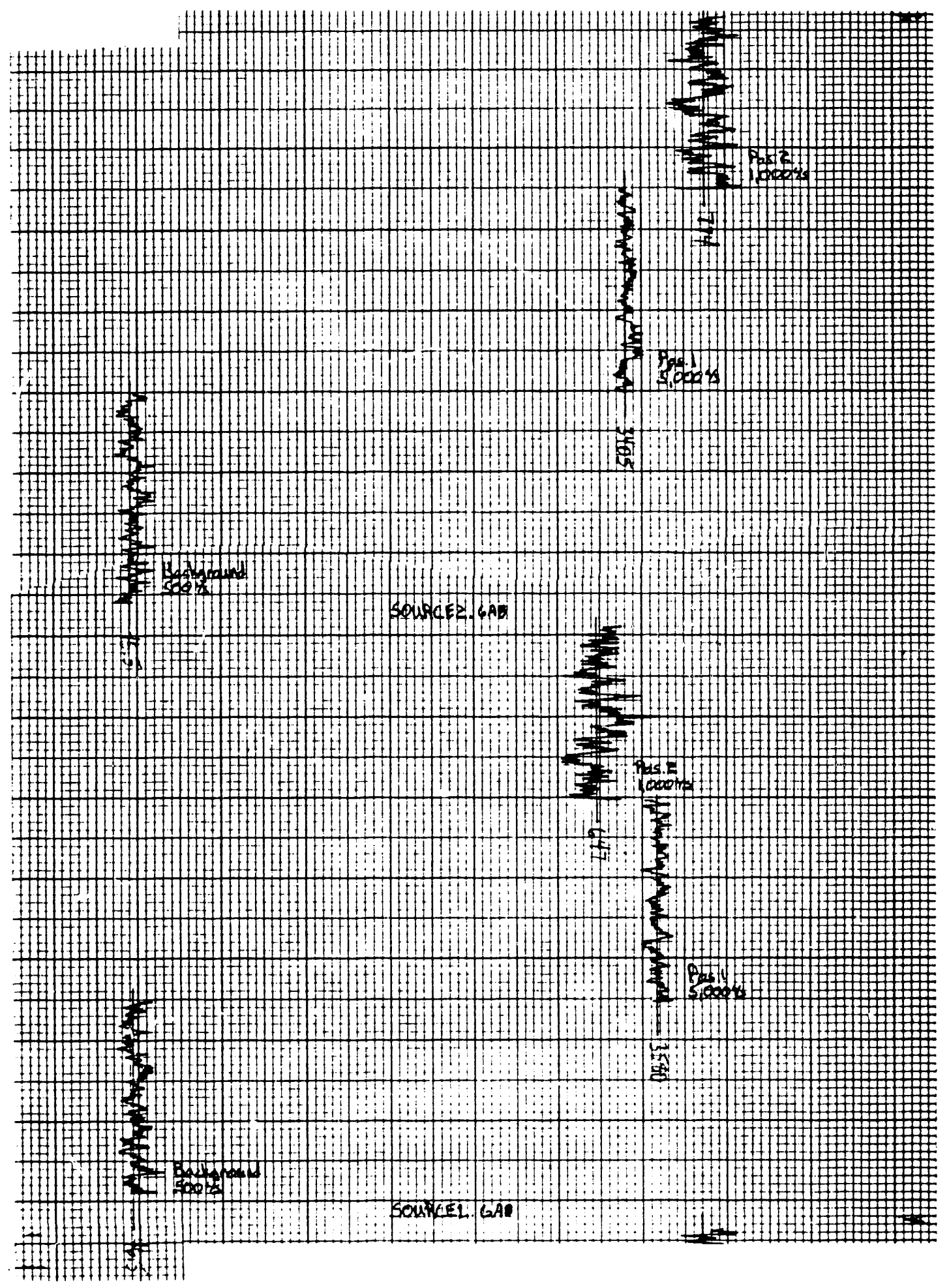

0.10 


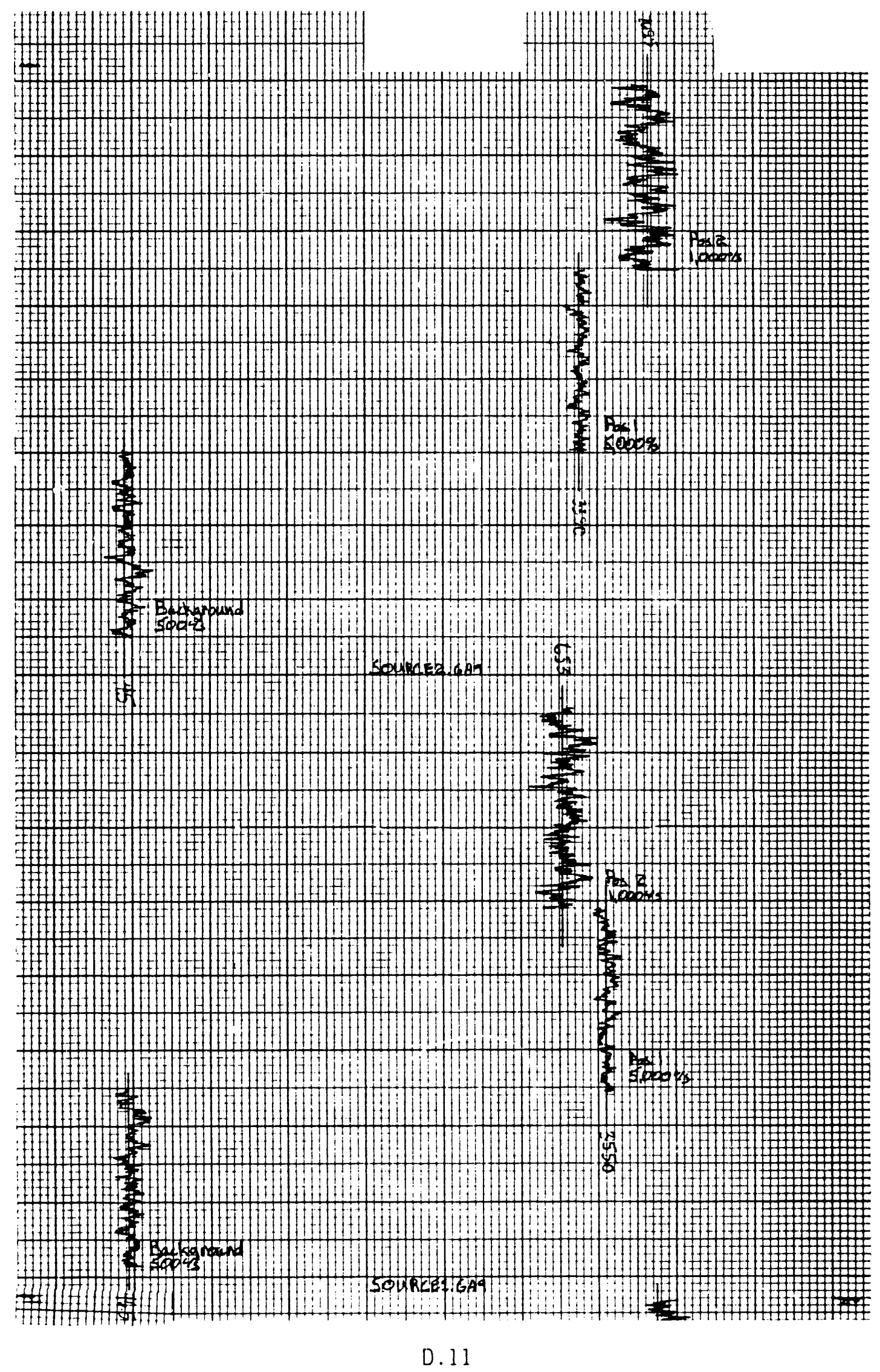




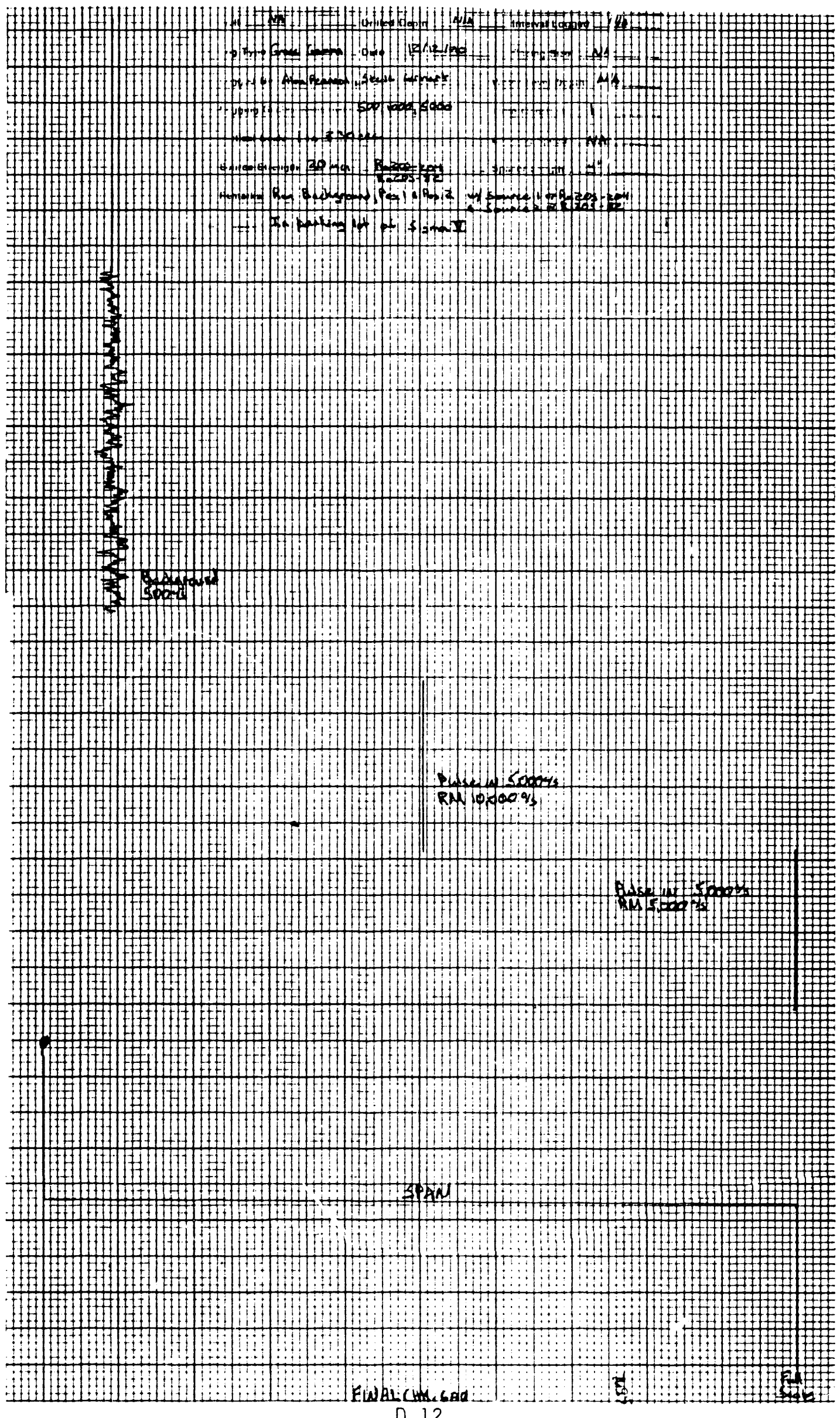




\section{DISTRIBUTION}

No. of

Copies

\section{OFFSITE}

2 DOE/Office of Scientific and Technical Information

\section{ONSITE}

\section{DOE Field Office, Richland}

E. A. Bracken

R. D. Hildebrand

M. W. Tiernan

Public Reading Room

16 Westinghouse Hanford Company
M. R. Adams
J. R. Brodeur
K. R. Fecht
B. H. Ford
M. C. Hagood
D. G. Horton
R. L. Jackson
C. J. Koizumi
S. E. Kos
A. G. Law
J. W. Lindberg
D. L. Lund
H. E. McGuire
R. K. Price
W. H. Price
L. C. Swanson

No. of

Copies

\section{Pacific Northwest Laboratory}

S. P. Airhart

R. J. Arthur (2)

B. N. Bjornstad

R. W. Bryce

M. A. Chamness

P. G. Doctor

R. M. Ecker

J. W. Falco

J. M. Hales

P. C. Hays/B. V. Johnston

D. K. Kreid

G. V. Last

T. L. Liikala

S. P. Luttrell

A. W. Pearson

J. R. Raymond

R. L. Skaggs

Publishing Coordination

Technical Report Files (5) 

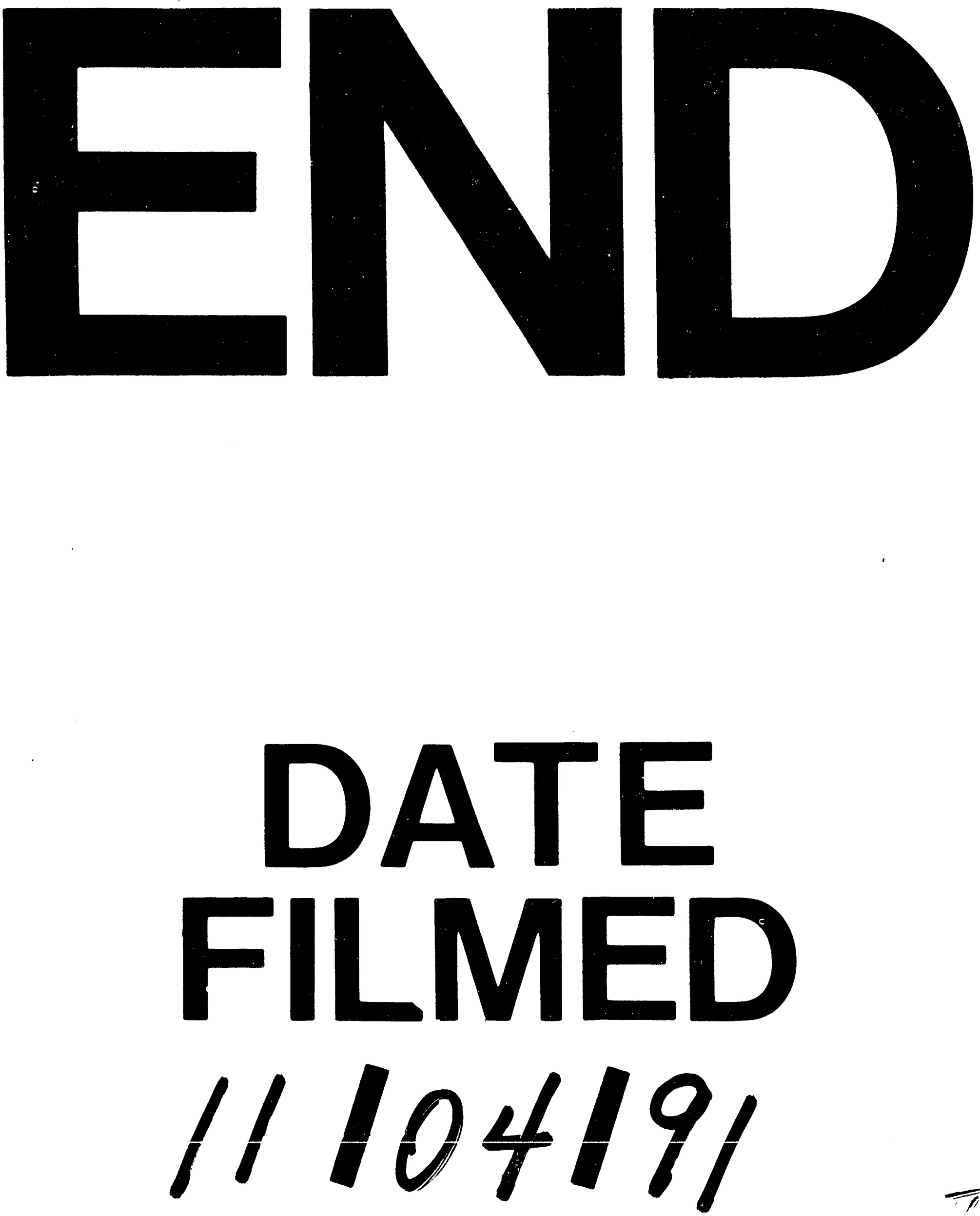

(1) 
